Article

\title{
Engineering Properties of Waste Sawdust-Based Lightweight Alkali-Activated Concrete: Experimental Assessment and Numerical Prediction
}

\author{
Hisham Alabduljabbar ${ }^{1}$, Ghasan Fahim Huseien ${ }^{2, * \mathbb{D}}$, Abdul Rahman Mohd Sam ${ }^{2}$, \\ Rayed Alyouef $1, * \mathbb{D}$, Hassan Amer Algaifi ${ }^{3}$ and Abdulaziz Alaskar ${ }^{4}$ \\ 1 Department of Civil Engineering, College of Engineering, Prince Sattam bin Abdulaziz University, \\ Alkharj 11942, Saudi Arabia; h.alabduljabbar@psau.edu.sa \\ 2 Construction Research Centre, Institute for Smart Infrastructure and Innovative Construction, \\ School of Civil Engineering, Faculty of Engineering, Universiti Teknologi Malaysia, \\ Johor Bahru 81310, Malaysia; abdrahman@utm.my \\ 3 Faculty of Civil and Environmental Engineering, Universiti Tun Hussein Onn Malaysia, \\ Parit Raja 86400, Malaysia; enghas78@gmail.com \\ 4 Department of Civil Engineering, College of Engineering, King Saud University, Riyadh 11362, Saudi Arabia; \\ abalaskar@ksu.edu.as \\ * Correspondence: fhghassan@utm.my (G.F.H.); r.alyousef@psau.edu.sa (R.A.)
}

Received: 7 November 2020; Accepted: 30 November 2020; Published: 2 December 2020

\begin{abstract}
Alkali activated concretes have emerged as a prospective alternative to conventional concrete wherein diverse waste materials have been converted as valuable spin-offs. This paper presents a wide experimental study on the sustainability of employing waste sawdust as a fine/coarse aggregate replacement incorporating fly ash (FA) and granulated blast furnace slag (GBFS) to make high-performance cement-free lightweight concretes. Waste sawdust was replaced with aggregate at $0,25,50,75$, and $100 \mathrm{vol} \%$ incorporating alkali binder, including 70\% FA and 30\% GBFS. The blend was activated using a low sodium hydroxide concentration (2 M). The acoustic, thermal, and predicted engineering properties of concretes were evaluated, and the life cycle of various mixtures were calculated to investigate the sustainability of concrete. Besides this, by using the available experimental test database, an optimized Artificial Neural Network (ANN) was developed to estimate the mechanical properties of the designed alkali-activated mortar mixes depending on each sawdust volume percentage. Based on the findings, it was found that the sound absorption and reduction in thermal conductivity were enhanced with increasing sawdust contents. The compressive strengths of the specimens were found to be influenced by the sawdust content and the strength dropped from 65 to $48 \mathrm{MPa}$ with the corresponding increase in the sawdust levels from $0 \%$ up to $100 \%$. The results also showed that the emissions of carbon dioxide, energy utilization, and outlay tended to drop with an increase in the amount of sawdust and show more the lightweight concrete to be more sustainable for construction applications.
\end{abstract}

Keywords: lightweight concrete; alkali-activated; waste sawdust; predicted engineering properties; sustainability

\section{Introduction}

Sawdust is a well-known agriculture and by-product waste material resulting from the wood industry. It is generated as a waste material when timbers are mechanically milled into different sizes and shapes. Many environmental problems are caused by sawdust wastes, wherein the scarcity of space for land fill is a major concern and a severe threat to developed nations. The excessive sawdust 
wastes that are accumulated due to the activities of factories, mills, and houses are ever growing annually. It is estimated that the annual generation of wood waste in the United States of America, Germany, the United Kingdom, and Australia is around 64, 8.8, 4.6, and 4.5 million tonnes per years, respectively, and more than $40 \%$ of these amounts are not recycled [1-4]. The high percentage of non-recycled wood wastes shows the deficiency of sufficient recycling procedures and strategies. Thus, it is vital to recycle wood wastes on a daily basis and utilize them effectively in cement-based composites/concretes to guarantee their harmless discarding as an environmental remedy.

Currently, researchers are facing a great challenge because of the constant increase in the demands of high-performance lightweight concretes (LWCs) as construction materials, where the manufacturing of novel construction materials from recycled industrial wastes has become a strategy. In this view, the advancement of LWCs via the use of sawdust wastes as lightweight aggregates is evaluated. The functions of sawdust in cements/concretes have been assessed by several researchers, and it has been used to make lightweight concretes in the past [5]. The thermal traits of sawdust-based cement composite have been reported [6], wherein its inclusion in the concrete matrix was found to significantly reduce the thermal conductivity by up to $20 \%$ compared to that of normal concrete ( $0 \%$ sawdust). Such a considerable decrease in the conductivity values was ascribed to the lowering in density and increased porosity of the lightweight concrete composites modified by sawdust wastes. Oyedepo et al. [7] used sawdust wastes as a substitute for fine aggregates (natural) at different contents from $0 \%$ up to $100 \%$ in standard heavyweight concretes, and showed that a ratio of more than $25 \%$ substitute to natural aggregates can negatively influence the concrete's strength properties and density. Other researchers have also made comparable observations when sawdust was used in concrete at various levels $(10 \%, 20 \%, 30 \%$, and $40 \%)$ as a substitute for sand. It was suggested that an amount of sawdust at up to $10 \%$ substitution for sand could produce a better density and mechanical strength of concrete [8]. Boob [9] also used sawdust as a substitute for fine aggregates (0-15\%) in concrete. Mageswari and Vidivelli [10] showed that sawdust ash as an agent to replace natural sand may be an appropriate choice for fine aggregates in concretes. It can significantly decrease the sawdust waste clearance problem and concurrently allow the conservation of natural fine aggregates. The authors found that concrete including sawdust possessed unique characteristics and presented better outcomes for the thermal and mechanical characteristics of the cement-based composite, making it economical compared to various other materials in the construction sector.

Lately, several products such as geopolymer and alkali-activated materials have been introduced as alternatives to conventional concrete and have emerged as constructional materials with lower $\mathrm{CO}_{2}$ footprints [11-17]. Alkali-activated pastes/mortars/concretes are inorganic polymers based on calcium $(\mathrm{CaO})$ and alumina-silicates (ASs) activated with alkaline activator solution. These are prepared from pozzolanic compounds via the alkali activation of $\mathrm{NaOH}$ and sodium silicates $(\mathrm{NaSi})[18,19]$. These binders obtained using alkali activation showed eco-friendliness due to the need for a modest quantity of energy in their fabrication process [20,21]. Following alkali activation, various solid wastes from different industries that contain $\mathrm{Si}, \mathrm{Al}$, and/or $\mathrm{Ca}$, including fly ash (FA), palm oil fuel ash (POFA), metakaolin, and granulated blast furnace slag (GBFS), have been used to make mortars/concretes [22-24].

Several researchers $[25,26]$ have observed that FA containing a high amount of $\mathrm{CaO}$ is also a proper resource material for producing high-performance geopolymer mortars and concretes. It was shown that the mixture of geopolymer prepared with FA class $\mathrm{C}$ (high $\mathrm{CaO}$ ) become curable at room temperature because of the $\mathrm{CaO}$-mediated reaction. Nevertheless, the geopolymerization of FA class $\mathrm{C}$ in the absence of additive was found to be very sluggish at ambient temperatures [27], achieving a low strength. Yet, the usage of materials containing a high amount of $\mathrm{CaO}$, including Ordinary Portland Cement (OPC), to enhance the strength of high-CaO FA-based geopolymer remains prospective [28]. Besides the generation of calcium-silicate-hydrate $(\mathrm{C}-\mathrm{S}-\mathrm{H})$ and calcium-aluminium-silicate-hydrate $(\mathrm{C}-\mathrm{A}-\mathrm{S}-\mathrm{H})$, the produced heat and water from the OPC-mediated reaction can help the geopolymerization process 
and thereby the development of strength enhancement [29]. By incorporating OPC and curing at $25^{\circ} \mathrm{C}$, high-Ca FA-based geopolymer mortars with a compressive strength (CS) of $65 \mathrm{MPa}$ were produced [30].

Amorphous GBFS, being one of the most popular industrial wastes, has been widely used to enhance normal concrete durability or fabricate cement-free mortars/concretes because of its excess contents of $\mathrm{Al}_{2} \mathrm{O}_{3}, \mathrm{CaO}$, and $\mathrm{SiO}_{2}$ in its chemical composition [31-35]. In alkaline media, GBFS shows both binding and pozzolanic properties [36]. Many investigations have detected [37] that the generation of excess Ca because of the addition of GBFS in FA geopolymer is accountable for the enhancement of the strength characteristics as well as the microstructure of the material. To evaluate the effectiveness of GBFS including FA as a geopolymer binder, the FA/GBFS ratio was widely varied together with the types, concentrations, and compositions of the activator in the mixture to produce them $[38,39]$. The inclusion of a high amount of Ca containing only $4 \%$ GBFS was found to enhance the strength of geopolymer [38]. Ismail et al. [40] evaluated the CS and hydration product of the FA and GBFS pastes and showed an enhancement in the CS of up to $50 \mathrm{MPa}$ at the curing age of 28 days. An elevation in the FA to GBFS ratio of as much as 1.0 was used and it was activated by $10 \mathrm{M}$ of $\mathrm{NH}$ solution, before curing at $25{ }^{\circ} \mathrm{C}$ was carried out. According to Ismail et al. [41], an early-age compressive strengths (CSs) of the FA/GBFS composite activated by the NH/NS may increase considerably with a minute quantity of hydrated lime. This FA geopolymer blended with slag exhibited an excellent mechanical and durability performance [42]. Previous studies have attempted to fabricate eco-friendly high-performance LWCs, cement-free concretes, and alkali-activated geopolymers, where the primary focus was to achieve improved strength and durability characteristics.

\section{Research Significance}

A comprehensive literature overview revealed that the potential usage of sawdust wastes for developing alkali-activated LWCs for the sustainable performance has not been widely explored yet. This work reports the effects of sawdust waste substitution for natural aggregates on the sustainability characteristics of LWCs with alkali activation containing FA and GBFS. These mixtures were made at changing levels of sawdust, including 70\% FA, 30\% GBFS, and alkali-activated solution to find the feasibility of recycling industrial wastes and transforming them into environmentally responsive, long-lasting, and sustainable lightweight concrete. Thus, natural aggregates were replaced by different levels of sawdust wastes $(0 \%, 25 \%, 50 \%, 75 \%$, and $100 \%)$ at a realistic working level with the appropriate physical conditions to make the alkaline solution-activated LWCs. All the synthesized specimens were analyzed by various measurements to evaluate the fresh, mechanical, and durability properties for obtaining an optimal composition.

\section{Experimental Details}

\subsection{Materials}

Furnace slag (GBFS of an off-white color) of a high purity was collected from a Malaysian industry (Ipoh, Malaysia) and utilized without further purification to produce cement-free binder. It was different from other supplementary components, with both cementitious and pozzolanic properties. It is obtained from the hydraulic chemical reactions upon mixing water. The X-ray fluorescence (XRF, HORIBA, Singapore, Singapore) spectra test of the slag showed the presence of Ca $(51.8 \%)$, silicate $(30.8 \%)$, and $\mathrm{Al}(10.9 \%)$. Low-level Ca containing FA (alumina-silicate material with a grey appearance) was obtained from a Malaysian power station (Tanjung bin, Johor, Malaysia) for producing the proposed AAMs. It fulfilled the requisites of the ASTM C618 for FA class F and contained Ca $(5.2 \%)$, silicate $(57.2 \%)$, and $\mathrm{Al}_{2} \mathrm{O}_{3}(28.8 \%)$. The particle median for the FA and slag (achieved by a particle size analyzer) was, respectively, 10 and $12.8 \mu \mathrm{m}$. The physical characteristics of both binder materials (GBFS and FA) were analyzed using the Brunauer Emmett Teller (BET, JEOL, Kuala Lumpur, Malaysia)) test with specific surface area $\left(18.1 \mathrm{~m}^{2} / \mathrm{g}\right.$ for FA and $13.6 \mathrm{~m}^{2} / \mathrm{g}$ for GBFS) calculations. 
Figure 1 presents the X-ray diffraction (XRD, Rigoku, Singapore, Singapore) pattern of GBFS and FA. The observed intense XRD peaks of FA at $2 \theta=16-30^{\circ}$ were due to the existence of polycrystalline silica and $\mathrm{Al}_{2} \mathrm{O}_{3}$. However, the prominent peaks at other angles were due to the existence of quartz and mullite crystallites. The absence of any sharp peak of GBFS verified its amorphous nature. The presence of silica and Ca peaks played an important role in the composition of GBFS and was beneficial for the AAM production. Conversely, the incorporation of FA was required to overcome the low level of $\mathrm{Al}_{2} \mathrm{O}_{3}(10.49 \%)$ in the slag.

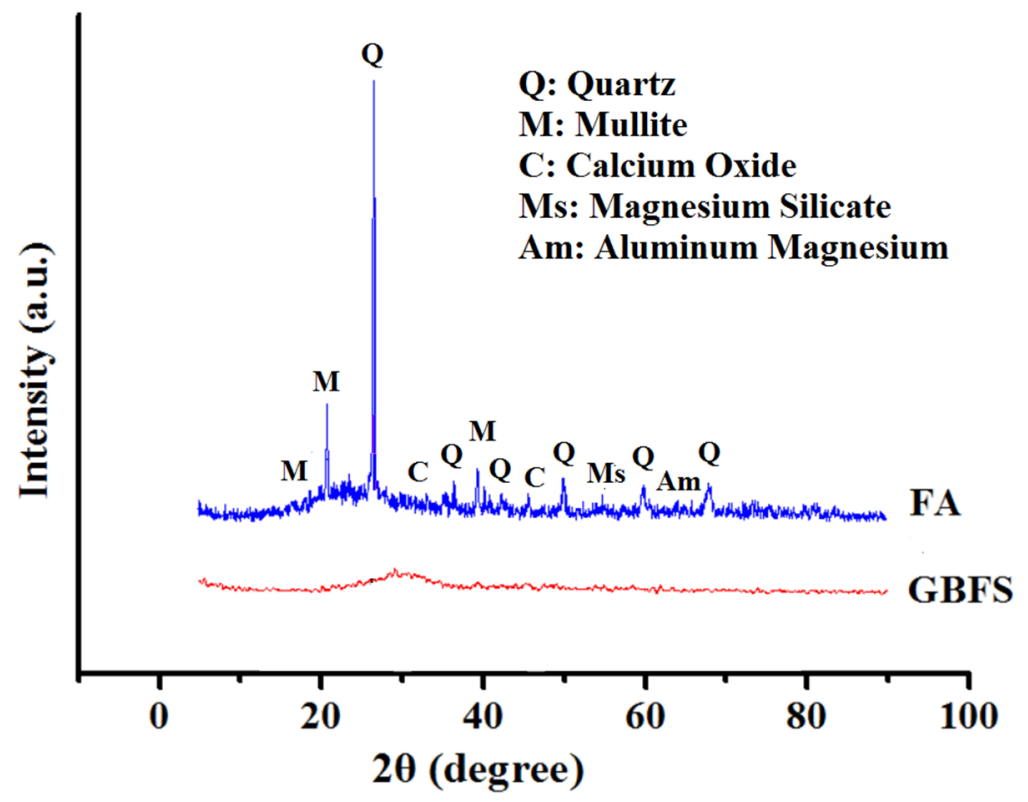

Figure 1. XRD diffractograms of fly ash (FA) and slag (GBFS).

Natural river sand was used as the fine aggregate to produce the control concrete samples. Following the ASTM C117 protocol, first the sand was washed in water to eliminate the silts and impurities [43], followed by the oven drying at $60{ }^{\circ} \mathrm{C}$ for $24 \mathrm{~h}$ to remove the moisture. The obtained clean sand fulfilled the ASTM C33-33M requisites [44]. The fineness modulus, specific gravity, and highest particle size of the prepared sand were $2.9,2.6$, and $2.36 \mathrm{~mm}$, respectively. Crushed garnet stone obtained from a quarry was used as a coarse aggregate in the sample preparation process. In producing conventional concrete, the size of the coarse aggregate plays an important role in ensuring that a good performance of concrete could be achieved. Therefore, the highest size of coarse aggregates was limited to below $8 \mathrm{~mm}$.

The sawdust wastes (No. 6013) were obtained (Figure 2) from the Malaysian (Syarikat Kilang Papan Chong Wah Sdn Bhd., Johor, Malaysia) wood industry. This local agro-waste ensured the acquirement from a single resource (density of $174 \mathrm{~kg} / \mathrm{m}^{3}$ and maximum size of $2.36 \mathrm{~mm}$ ) for the fine aggregate use. Sawdust with a density of $182 \mathrm{~kg} / \mathrm{m}^{3}$ and a maximum size of $6 \mathrm{~mm}$ was utilized as a coarse aggregate to prepare the LWC. The main attributes of the sawdust include the chemical composition and the loss of ignition (LOI), as shown in Table 1. The primary constituent of the sawdust was cellulose (87\% of the total mass) and low amounts of $\mathrm{CaO}$ and $\mathrm{Al}_{2} \mathrm{O}_{3}$. The LOI percentage of the sawdust from the total mass was found to be $4.76 \%$.

Table 1. Chemical constituents (in \%) of the waste sawdust.

\begin{tabular}{|c|c|c|c|c|c|c|}
\hline \multicolumn{7}{|c|}{ Chemical Compositions (\%) } \\
\hline Cellulose & $\mathrm{Al}_{2} \mathrm{O}_{3}$ & $\mathrm{Fe}_{2} \mathrm{O}_{3}$ & $\mathrm{CaO}$ & $\mathrm{MgO}$ & $\mathrm{K}_{2} \mathrm{O}$ & LOI \\
\hline 87.0 & 2.5 & 2.0 & 3.50 & 0.23 & 0.01 & 4.76 \\
\hline
\end{tabular}




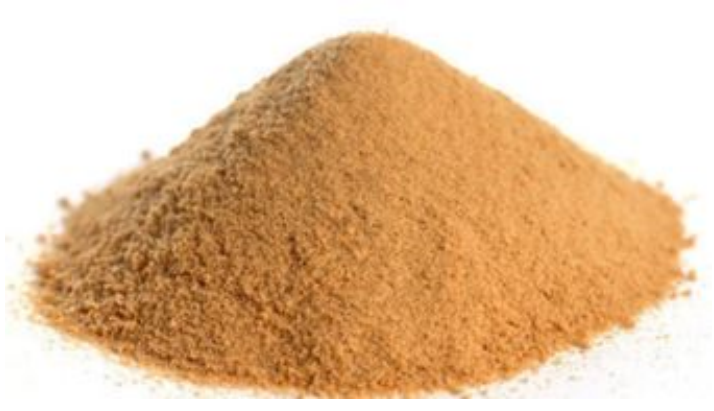

(a)

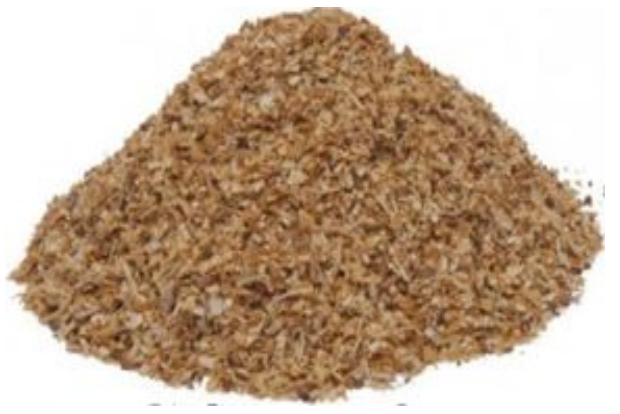

(b)

Figure 2. (a) Fine sawdust, (b) coarse sawdust.

The solution (S) for the alkaline activation was made of sodium hydroxide (NH) and sodium silicate (NS). It was used to dissolve the alumina-silicate from FA and GBFS. Analytical-grade NH (98\% purity) pellets were dissolved in water to prepare a solution of $13.7 \%$ of $\mathrm{Na}_{2} \mathrm{O}$ and $86.3 \%$ of $\mathrm{H}_{2} \mathrm{O}$ (2 M). A high-purity NS mixture was prepared using $\mathrm{SiO}_{2}\left(29.5 \mathrm{wt}\right.$. \%), $\mathrm{Na}_{2} \mathrm{O}(14.70 \mathrm{wt} . \%)$, and $\mathrm{H}_{2} \mathrm{O}$ (55.80 wt.\%). The obtained $\mathrm{NH}$ solution $(2 \mathrm{M})$ was first stored for $24 \mathrm{~h}$ at room temperature and later

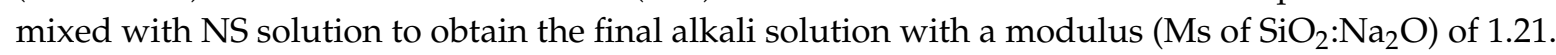
The ratio of the NS to NH for all the alkali solutions was kept constant at 0.75 .

\subsection{Mix Designs of Prepared Concretes}

For all the LWC specimens, the values of the alkaline solution to binder ratio (S:B) and the binder content were fixed with 0.40 and $450 \mathrm{~kg} / \mathrm{m}^{3}$, respectively. Waste products such as FA and GBFS were utilized for fabricating LWC mixes with constant amounts of 70\% and $30 \%$, respectively, as sources of $\mathrm{SiO}_{2}, \mathrm{Al}_{2} \mathrm{O}_{3}$, and $\mathrm{CaO}$. A blend containing $100 \%$ natural aggregates (sand and gravels) was made and regarded as the control sample (Table 2). The molarity of the NH, NS to NH, and alkaline solution modulus (Ms) was fixed for all concrete mixtures. The influence of various contents of fine and coarse sawdust as a natural aggregate replacement on the LWC design is shown in Table 2. Four replacement contents were used to evaluate the effects of sawdust waste on the proposed concrete's weight, strength, and geopolymerization process.

Table 2. Mix design of the proposed lightweight alkali-activated concrete $\left(\mathrm{Kg} / \mathrm{m}^{3}\right)$.

\begin{tabular}{|c|c|c|c|c|c|c|c|c|}
\hline \multirow[b]{2}{*}{ Mix } & \multicolumn{2}{|c|}{ Binder $\left(\mathrm{kg} / \mathrm{m}^{3}\right)$} & \multicolumn{2}{|c|}{ Solution $\left(\mathrm{kg} / \mathrm{m}^{3}\right)$} & \multicolumn{4}{|c|}{ Fine and Coarse Aggregates $\left(\mathrm{kg} / \mathrm{m}^{3}\right)$} \\
\hline & FA & GBFS & NH & NS & $\begin{array}{l}\text { River } \\
\text { Sand }\end{array}$ & $\begin{array}{c}\text { Crushed } \\
\text { Gravel }\end{array}$ & $\begin{array}{c}\text { Fine } \\
\text { Sawdust }\end{array}$ & $\begin{array}{l}\text { Coarse } \\
\text { Sawdust }\end{array}$ \\
\hline S0 & & & & & 845 & 950 & 0 & 0 \\
\hline $\mathrm{S} 25$ & & & & & 634 & 712 & 22 & 26 \\
\hline S50 & 315 & 135 & 104 & 78 & 422 & 475 & 45 & 47 \\
\hline S75 & & & & & 211 & 237 & 67 & 71 \\
\hline S100 & & & & & 0 & 0 & 90 & 95 \\
\hline
\end{tabular}

\subsection{Fresh and Hardened Concretes Tests Program}

Prior to the mixing and casting, the internal surface of the molds was greased with engine oil to make the de-molding process easy. A homogeneous alkali solution composed of NH and NS was cooled at ambient atmosphere and then used for the concrete preparation. Uniform mixtures of fine/coarse aggregates were made by blending FA/GBFS for approximately $4 \mathrm{~min}$ at dry conditions. Next, the prepared mixes were alkali-activated. The whole concrete matrix was mixed for 4 min once more via a machine controlled at an average speed. The achieved fresh green concretes were cast within the molds in three layers, wherein every layer was strengthened via the vibration table for $30 \mathrm{~s}$ 
to remove air voids. Upon the completion of the casting process, the casted concretes were cured at $27 \pm 1.5^{\circ} \mathrm{C}$ (for $24 \mathrm{~h}$ at relative humidity of $75 \%$ ). Finally, the concrete mixes were de-molded and stored under identical settings for further testing and analyses.

Following the ASTM C143 and C191 protocols, the slump and setting time values were measured, respectively. The CS measurements were conducted in cubic-shaped molds of size $100 \times 100 \times 100 \mathrm{~mm}$ which were adequately cured for 1, 3, 7, 28, 56, and 90 days following the ASTM C579 specification. These CS tests were performed following the ASTM C109-109M standard, where three sets of samples were analyzed at each curing age. A load at constant rate $(2.5 \mathrm{kN} / \mathrm{s})$ was subjected to test the failure of these specimens. Since the machine has inbuilt configurations, the density and CS were generated automatically depending on the imputed specimen weight and dimensions. A prism-shaped sample with the dimensions of $100 \mathrm{~mm} \times 100 \mathrm{~mm} \times 500 \mathrm{~mm}$ were cast for flexural strength (FS) and drying shrinkage (DS) tests following the ASTM C78 and C157 stipulations, respectively. The average readings of the three tested concrete mixes at the curing ages of $3,7,14,21,28,56$, and 90 days were considered to assess the DS value of each mix. According to the ASTM C496 standard, cylindrical-shaped specimens (diameter of $100 \mathrm{~mm}$ and depth of $200 \mathrm{~mm}$ ) were prepared for a splitting tensile strength (STS) evaluation. A water absorption (WA) test was performed following the ASTM C642 specification, wherein mixes of size $100 \mathrm{~mm} \times 100 \mathrm{~mm} \times 100 \mathrm{~mm}$ were molded. The specimens were immersed in water at $27^{\circ} \mathrm{C}$ for $24 \mathrm{~h}$ after they matured. Later, these specimens were suspended and completely submerged in water to measure their weight (Ms). Subsequent to the saturation, all the specimens were dried in a ventilated oven at $105^{\circ} \mathrm{C}$ for over $24 \mathrm{~h}$ then weighed (Md). The WA of the proposed LWCs was calculated from the average value of the three samples via the relation:

$$
\mathrm{WA}(\%)=\frac{\mathrm{Ms}-\mathrm{Md}}{\mathrm{Md}} \times 100
$$

\subsection{Artificial Neural Network (ANN) Model}

In this work, the ANN model was utilized to explain the CS of the alkali-activated concretes for obtaining the optimum values of the affecting parameters. In addition, it was intended to reduce both time and cost. The model was inspired by a natural human process. The developed model consists of three layers, as shown in Figure 3. The first layer-namely, input layer (I)—contains five neurons (parameters), which are represented by molarity, NS/NH, yeast solution to binder, GBFS/FA, and time. Then, fourteen neurons of the hidden layer $(\mathrm{H})$ were used to achieve the best performing model. Meanwhile, one neuron in the third layer was used to reflect the predicted compressive strength-namely, the output layer $(\mathrm{O})$.

A total of 144 experimental works were utilized to construct the proposed ANN model in MATLB. In particular, the feed-forward back-propagation network architecture was created using a newff function. In addition, the sigmoid function was adopted to map the input with the target output, as shown in Equation (2).

$$
f(x)=\frac{1}{1+e^{-x}}
$$

As much as $75 \%$ of the experimental data was used for training using the Levenberg-Marquardt (LM) algorithm in order to minimize error. Meanwhile, $15 \%$ and $10 \%$ of the experimentally measured values were utilized to test and validate the proposed model, respectively. Equation (3) was used to convert the experimental data values to normalized ones. The normalized values were ranged between 0.1 and 0.9 , aiming to avoid any scaling impact. Here, $X i$ is the input or output value, while Xmax and $\mathrm{Xmin}$ are the corresponding highest and lowest values. Furthermore, the performance of the proposed model was evaluated based on both the coefficient of correlation $\left(R^{2}\right)$ and error, with a performance goal of 0.01 and learning rate of 0.2 .

$$
X n o r m=0.8 \times\left(\frac{X i-X \min }{X \max -X \min }\right)-0.1
$$




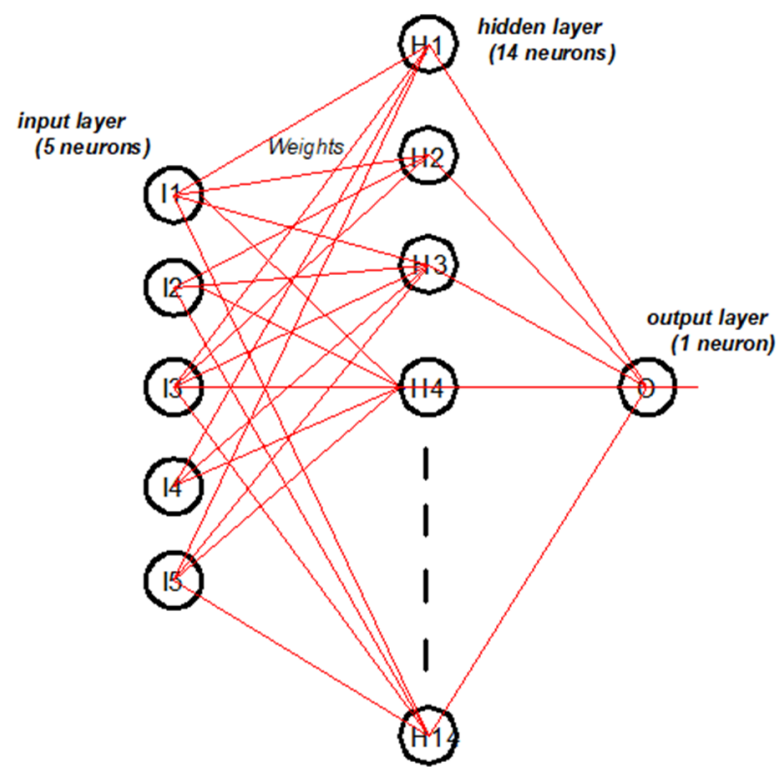

Figure 3. Artificial neural network processing.

The correlation coefficient $\left(R^{2}\right)$ was also taken into account as a statical estimator. In particular, it was utilized to evaluate the strength of the results. In addition, $R^{2}$ is able to provide insight into the degree of fitting between the network output and the collected experimental data, as expressed in Equation (4). Accordingly, Yactual was the experimental result of the concrete strength and Ymodel was the predicted concrete strength from the model. In addition, the average value of the predicted results was termed Ymodel mean, whereas the number of experimental runs was represented by $\mathrm{N}$. Moreover, the best fitting of the actual CS of the alkali-activated and the predicted results was accrued by increasing the value of the correlation coefficient, wherein the values usually ranged from $0-1$.

$$
R^{2}=\frac{\sum_{i=1}^{n}\left(\text { Yacual }-Y_{\text {model mean }}\right)^{2}-\sum_{i=1}^{n}\left(Y_{\text {model }}-Y_{\text {actual }} i\right)}{\sum_{i=1}^{n}\left(\text { Yacual }-Y_{\text {model mean }}\right)}
$$

\subsection{Sound Absorption}

The acoustic energy absorption, reflection, and dissipation capacity of the material were obtained from the sound absorption measurements. In accordance to the ASTM E1050 stipulation, the two-microphone transfer-function (impedance tube) method was used to determine the impedance and absorption of the acoustic specimens. This method is intended for measuring the absorption coefficient and the particular acoustic impedance of sound-absorbing materials that are circular-cut in small samples, normally in the 100 to $6000 \mathrm{~Hz}$ frequency range (Figure 4).

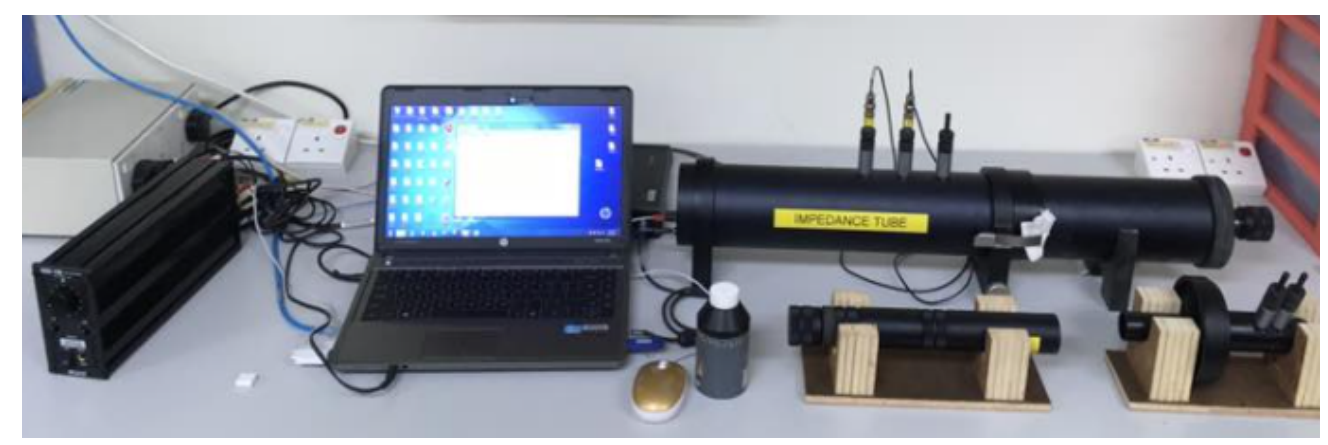

Figure 4. Impedance tube instrument. 


\subsection{Heat Transfer Measurement}

In developed countries, buildings are large consumers of energy and saving energy is the main concern. The energy consumed in buildings can be saved effectively by increasing their thermal insulation, which is vital for countries with hot and cold climates and a high energy demand. Thermal insulation is required to decrease the total energy usage in buildings and add to unusual regenerative energy resources for sustainability. The heat transfer was measured for the cylindrical specimen of diameter $150 \mathrm{~mm}$ and height $300 \mathrm{~mm}$. After 28 days of casting, the dried surface of the specimen was covered by a plastic sheet to prevent the excess entry of water. A PVC pipe ( $20 \mathrm{~mm}$ of diameter) was used to protect the thermocouple from unexpected impacts. All the samples were put in a water container at $34^{\circ} \mathrm{C}$. Then, the temperature of the water was slowly increased up to $100{ }^{\circ} \mathrm{C}$, wherein the first measurement was conducted. Next the heater was turned on to record the interior temperature of the specimen using a K thermocouple, data loggers, and computers. During the immersion of the sawdust concretes in water, the temperature of the heater was increased, thereby increasing the water volume. Such a rising temperature of water was recorded at close intervals in the first $24 \mathrm{~h}$ up to $100{ }^{\circ} \mathrm{C}$. However, the transferred heat was measured later and rather frequently until the water temperature came down to boiling point.

\subsection{Environmental and Economic Benefits}

For lightweight concretes to be a practicable product like the traditional one, they must have a lower or comparable cost for the user, considerably improved function or ease of manufacture, or other sustainability benefits. To compare the sawdust-based concretes with the conventional one in terms of sustainability, three headline metrics were selected, such as the carbon dioxide emissions, the usage of energy (direct fuel consumption), and the total production cost. These matrices were used to argue in favor or against the usage of sawdust-based lightweight concretes. However, other key factors that have considerable roles are technical presentation, leaching, water consumption, contents of harmful materials, release of other greenhouse gases, and waste volume amount. These metrics can be avoided using sawdust in an activated alkaline solution or sand and gravel-based concretes. Actually, the chosen 3 metrics are used to quantify the development of alkaline solution-activated lightweight concretes in the industry at early stages.

The $\mathrm{CO}_{2}$ emission, energy usage, and cost were derived via the life cycle approach. This evaluation implied the requirement of feed stocks for manufacturing the aggregates and the related transport cost. It allowed a valid comparison among sawdust, sand, and gravel, wherein the production impact was unable to provide a complete depiction of the energy demand and the $\mathrm{CO}_{2}$ emission from the feedstock. These do not include factors such as the mixing, laying, and curing of the alkaline solution-activated concrete and the operation life span emission, assuming them to be alike for every product. This strategy is comparable in terms of the life cycle impacts rather than the absolute impacts. As an effective method for comparable products, it lowers the required evaluation time.

Following the life cycle of every material, the outlay, the amount of $\mathrm{CO}_{2}$ release, and the energy requirements were estimated. The life cycle of fine and coarse sawdust includes the collection and transport stages. The collection cost of sawdust wastes from the factory was negligible. The distance for the transportation of each substance was added in the life cycle estimate. The distance for the gravel transportation was longer $(60 \mathrm{~km})$ compared to that of sand $(49 \mathrm{~km})$ and sawdust $(5 \mathrm{~km})$. The fuel cost of transports, including the kinds of trucks, volume, speed, and cost for 1 tone/km, were same for every type of material. Table 3 lists the machineries and materials needed for life cycle calculation. The total $\mathrm{CO}_{2}$ emission and cost of the fine/coarse aggregates were calculated relative to each material, where the total diesel consumption depended on the transportation distance (Table 3). Likewise, the total energy required for each mix was estimated depending on the diesel cost of every type of material, including crushing and transportation. Equations (5)-(7) were adopted to calculate the total $\mathrm{CO}_{2}$ emissions, cost, and energy consumption for each meter cubic of material. The total amounts of $\mathrm{CO}_{2}$ emission, outlay, and energy utilization for every material are listed in Table 4. 
Table 3. Machine and material information for the life cycle calculation.

\begin{tabular}{cc}
\hline Item & Value \\
\hline Speed of truck, $\mathrm{km} / \mathrm{h}$ & 80 \\
Diesel cost, $\mathrm{L} / \mathrm{km}$ & 0.09 \\
Diesel cost, $\mathrm{RM} / \mathrm{L}$ & 2.18 \\
Truck capacity, $\mathrm{m}^{3}$ & 12 \\
Transportation cost of $1 \mathrm{~m}^{3}, \mathrm{RM} / \mathrm{km}$ & 0.75 \\
Density natural coarse aggregate, $\mathrm{kg} / \mathrm{m}^{3}$ & 1820 \\
Density of river sand, $\mathrm{kg} / \mathrm{m}^{3}$ & 1640 \\
Fine sawdust density, $\mathrm{kg} / \mathrm{m}^{3}$ & 176 \\
Coarse sawdust density, $\mathrm{kg} / \mathrm{m}^{3}$ & 182 \\
$\mathrm{CO}_{2}$ release for $1 \mathrm{~L}$ diesel, ton & 0.0027 \\
Energy cost for $1 \mathrm{~L}$ diesel, $\mathrm{GJ}$ & 0.0384 \\
\hline
\end{tabular}

Table 4. The $\mathrm{CO}_{2}$ release, expenditure, and energy use of every material depended on life cycle.

\begin{tabular}{cccc}
\hline Material & $\mathbf{C O}_{\mathbf{2}}$ Emission, ton $/ \mathbf{m}^{\mathbf{3}}$ & Cost, $\mathbf{R M} / \mathbf{m}^{\mathbf{3}}$ & Energy Consumption, $\mathbf{G J} / \mathbf{m}^{\mathbf{3}}$ \\
\hline Sand & 0.009 & 55 & 0.134 \\
Gravel & 0.012 & 65 & 0.148 \\
Fine sawdust & 0.0006 & 34.5 & 0.018 \\
Coarse sawdust & 0.0008 & 36 & 0.021 \\
\hline
\end{tabular}

Total $\mathrm{CO}_{2}$ emission

$$
\sum_{i=1}^{n} m i[(d i \times D i \times k 1 i)+(E i \times k 2 i)]
$$

where $m i$ is the mass of component $i\left(\operatorname{ton} / \mathrm{m}^{3}\right), d i$ is the transport distance $(\mathrm{km}), D i$ is the diesel consumption $(\mathrm{L} / \mathrm{km}), k 1 i$ denotes the $\mathrm{CO}_{2}$ emission for 1 Liter diesel in tonnes, Ei represents the total electricity consumption $(\mathrm{kWh})$, and $k 2 i$ is the $\mathrm{CO}_{2}$ emission for $1 \mathrm{kwh}$ electricity in tonnes.

Total energy consumption:

$$
\sum_{i=1}^{n} m i[(d i \times D i \times k 3 i)+(E i \times k 4 i)]
$$

where $k 3 i$ is the energy consumption for $1 \mathrm{~L}$ diesel in GJ, $E i$ is the total electricity consumption (kWh) and $k 4 i$ is the energy consumption for $1 \mathrm{kwh}$ electricity in GJ.

Total cost:

$$
\sum_{i=1}^{n} m i[(d i \times D i \times D P i)+T i+(E i \times E P i)]
$$

where $D P i$ is the diesel cost $(\mathrm{RM} / \mathrm{L})$, Ti is the transport charge of $1 \mathrm{~m}^{3}(\mathrm{RM} / \mathrm{km})$, and $E P i$ is the electricity cost $(\mathrm{RM} / \mathrm{kWh})$.

\section{Results and Discussion}

\subsection{Workability and Setting}

Figure 5 illustrates the slump values of the prepared concretes depending on the waste sawdust replacement levels of both sand and gravel. The results of the slump reading showed that an increasing content of sawdust replacing natural aggregates reduced the workability of the prepared concretes. The value of slump was dropped from 130 to 116, 102, 91, and $74 \mathrm{~mm}$ with a rise in the level of replacement of sand and gravel by sawdust from 0 to 25,50,75, and 100\%, respectively. Typically, the concrete workability was reduced with the rise in the sawdust amounts in the mixtures. Nevertheless, the influence was more prominent at higher sawdust contents (100\%). Generally, the workability of the concrete was affected by the specific surface area of the sawdust and the high water demand with a high level of sawdust in the matrix. In another way, the usage of sawdust wastes as fine/coarse aggregates essentially enhanced the concretes' texture with several other uneven and very rough fine 
porous particles. Therefore, it improved the inter-particle friction accountable for impeding the fresh concrete flow. For a constant solution to binder ratio, the workability of the concretes was reduced with the increase in the sawdust amount as a substitute for river sand and crushed gravel. Several researchers [45-47] have obtained similar trends of results for the reduction in the workability of concrete containing lightweight aggregates. The limitations associated with the workability decrease in the concrete mixes due to the utilization of sawdust wastes as substitute for natural sand can be overcome by applying super-plasticizer.

Both the initial and final setting times of the concretes produced using various amounts of the waste sawdust as fine and coarse aggregates are presented in Figure 6. Clearly, both the initial and final setting times were decreased with the increase in the sawdust levels in the concretes. For the initial setting time, the reading was decreased from 39 to $37,34,31$, and $28 \mathrm{~min}$, respectively, with an increase in the content of sawdust from 0 to $25,50,75$, and $100 \%$. A similar trend was found with the final setting time and reading, which was increased from 61 to 56, 53, 48, and $46 \mathrm{~min}$. However, the initial and final setting time difference for each mixture was decreased with the increase in the sawdust content. Further, the difference in the setting time of each mixture is not large. The reduction in setting time with the increase in the content of sawdust addressed the high water demand of sawdust, which affected the geopolymerization process and the dissolving of alumina-silicate and calcium. An inverse relationship was observed between the sawdust waste content and the setting time of the prepared concrete. The high absorption of sawdust to alkaline solution imparted a high viscosity to the mix, which hardened rapidly. Meanwhile, the inclusion of sawdust in concrete mixtures with comparatively higher water absorptions than river sand and gravel hardened the alkaline solution-activated mixes more rapidly and decreased the setting time because of the adsorption of additional water by sawdust. Conversely, the inclusion of sawdust wastes in the alkaline system led to a reduction in the $\mathrm{pH}$ because of the decomposition of lignin mediated by the $\mathrm{pH}$ changes in the porous solution. The present outcomes are analogous to the findings of Duan et al. [48], where both the initial and final setting times were reduced for the concretes made with sawdust.

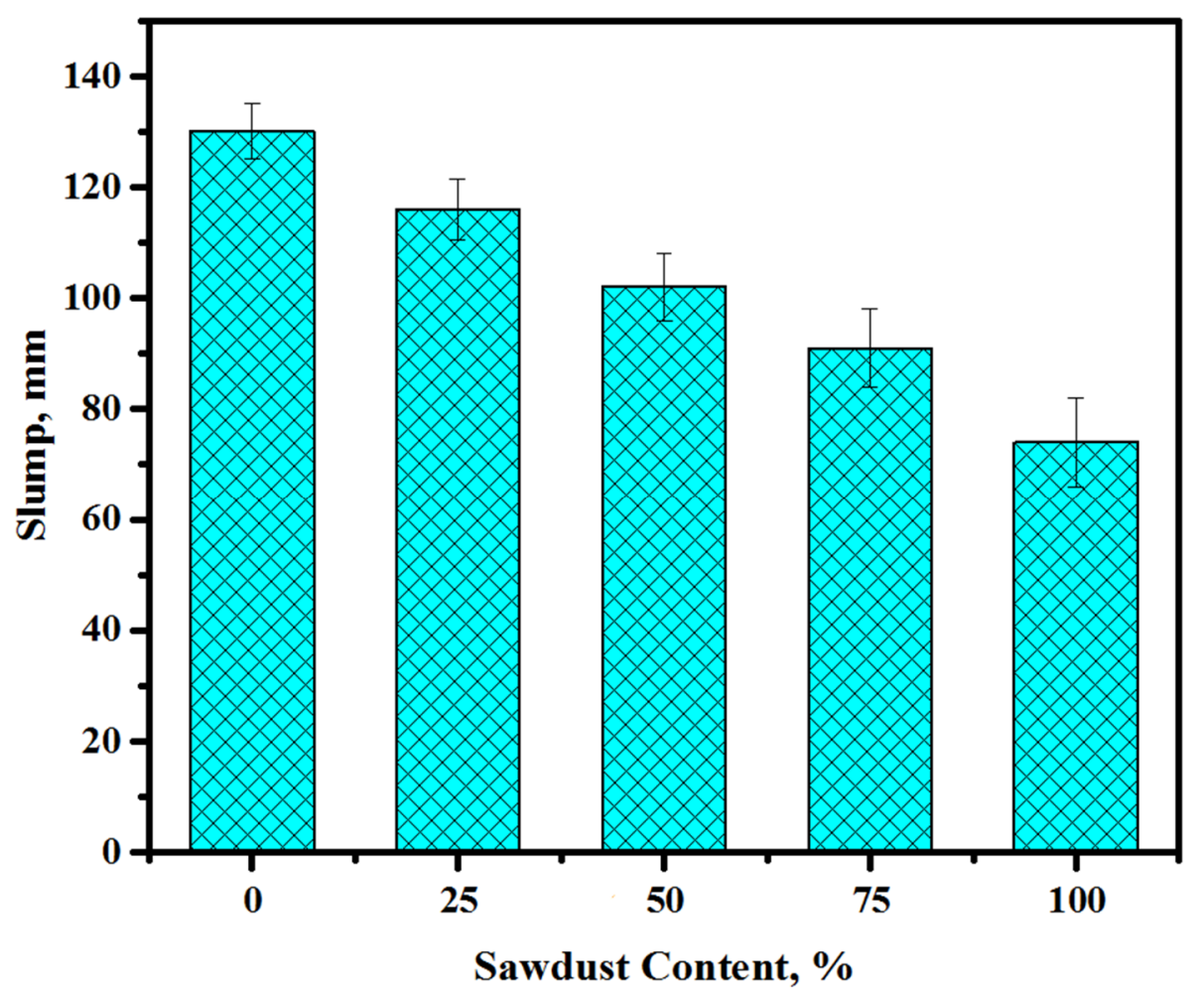

Figure 5. Slump values of the prepared alkali-activated concretes. 


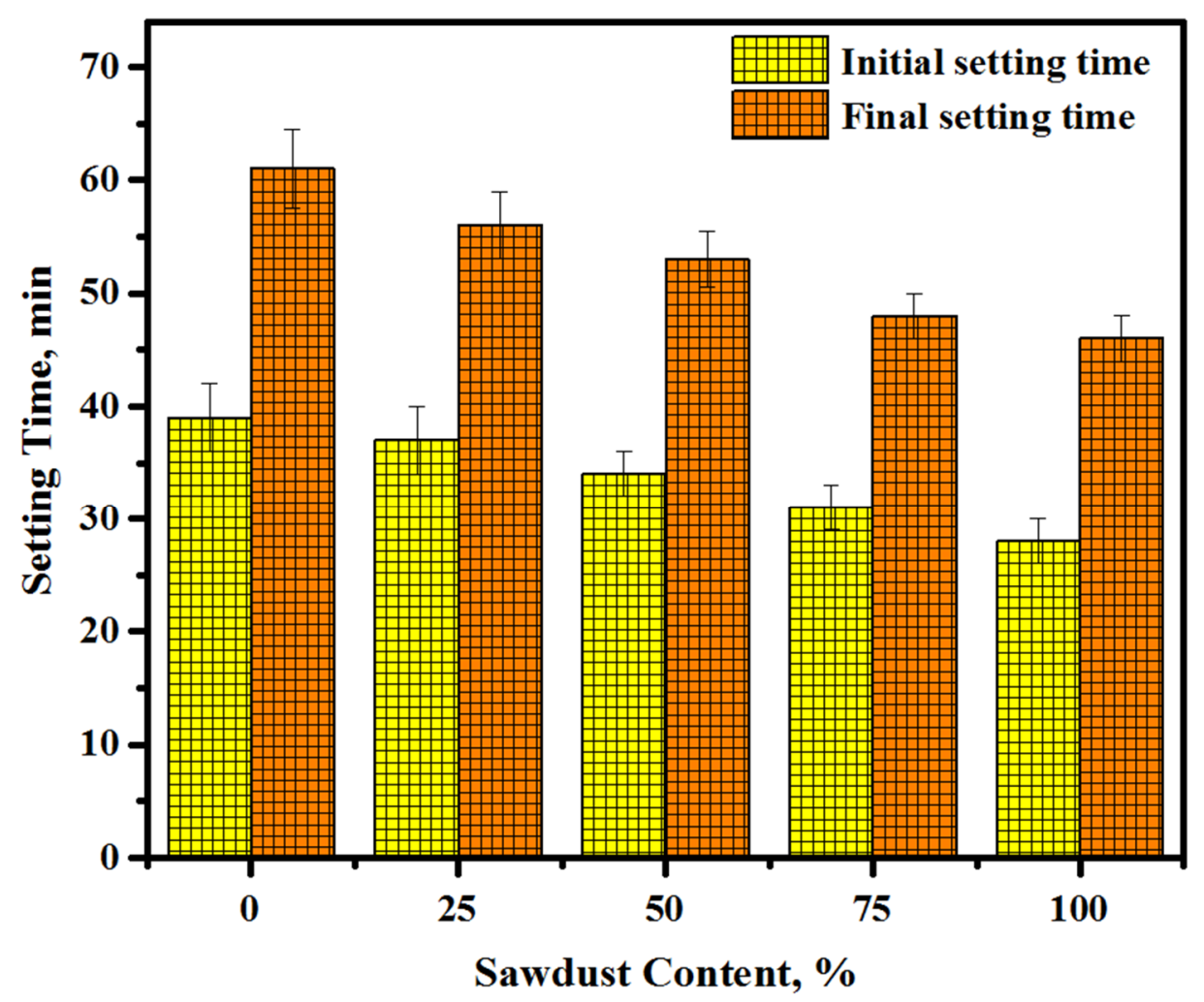

Figure 6. Effect of the sawdust content on the concretes' initial and final setting times.

\subsection{Hardened Density and Ultrasonic Pulse Velocity}

Figure 7 depicts the hardened density values of the prepared concrete containing waste sawdust as a river sand and crushed gravel replacement at the curing age of 28 days. The densities of the prepared concretes were reduced from 2.28 to $1.98,1.63,1.24$, and $0.89 \mathrm{ton} \cdot \mathrm{m}^{-3}$ when the content of sawdust was increased from 0 to $25,50,75$, and $100 \%$, respectively. The mixture containing $100 \%$ sawdust displayed the lowest density $\left(0.89 \mathrm{ton} \cdot \mathrm{m}^{-3}\right)$. In addition, the low specific gravity and porosity of the sawdust considerably influenced the densities of the prepared concretes. The present outcome is consistent with the one obtained by Memon et al. [49] for concrete including a high volume of sawdust as a coarse aggregate. Likewise, these findings contributed to improving and developing the high-performance lightweight alkali-activated concrete, which was supported by the results reported by Sales et al. [50]. They assessed the possible uses of lightweight concretes made from coarse aggregates via water treatments of sludge and sawdust.

Figure 8 shows the influence of various sawdust amounts on the ultrasonic pulse velocity (UPV) values of the prepared concretes. An increase in the sawdust level from 0 to 25, 50, 75, and 100\% caused reductions in the corresponding UPV readings of the concretes from 3.42 to 3.02, 2.79, 2.57, and $2.32 \mathrm{~km} / \mathrm{s}$ at 28 days of curing age. This drop was due to the porous nature of the sawdust, which negatively influenced the densities and microstructures of the prepared concrete. It is evident that, with the increasing content of sawdust and decreasing amount of river sand/crushed gravel, the UPV of the prepared concretes was decreased, which was ascribed to the increase in the sawdust-mediated porosity. The present findings agreed well with those of a previous study [47]. 


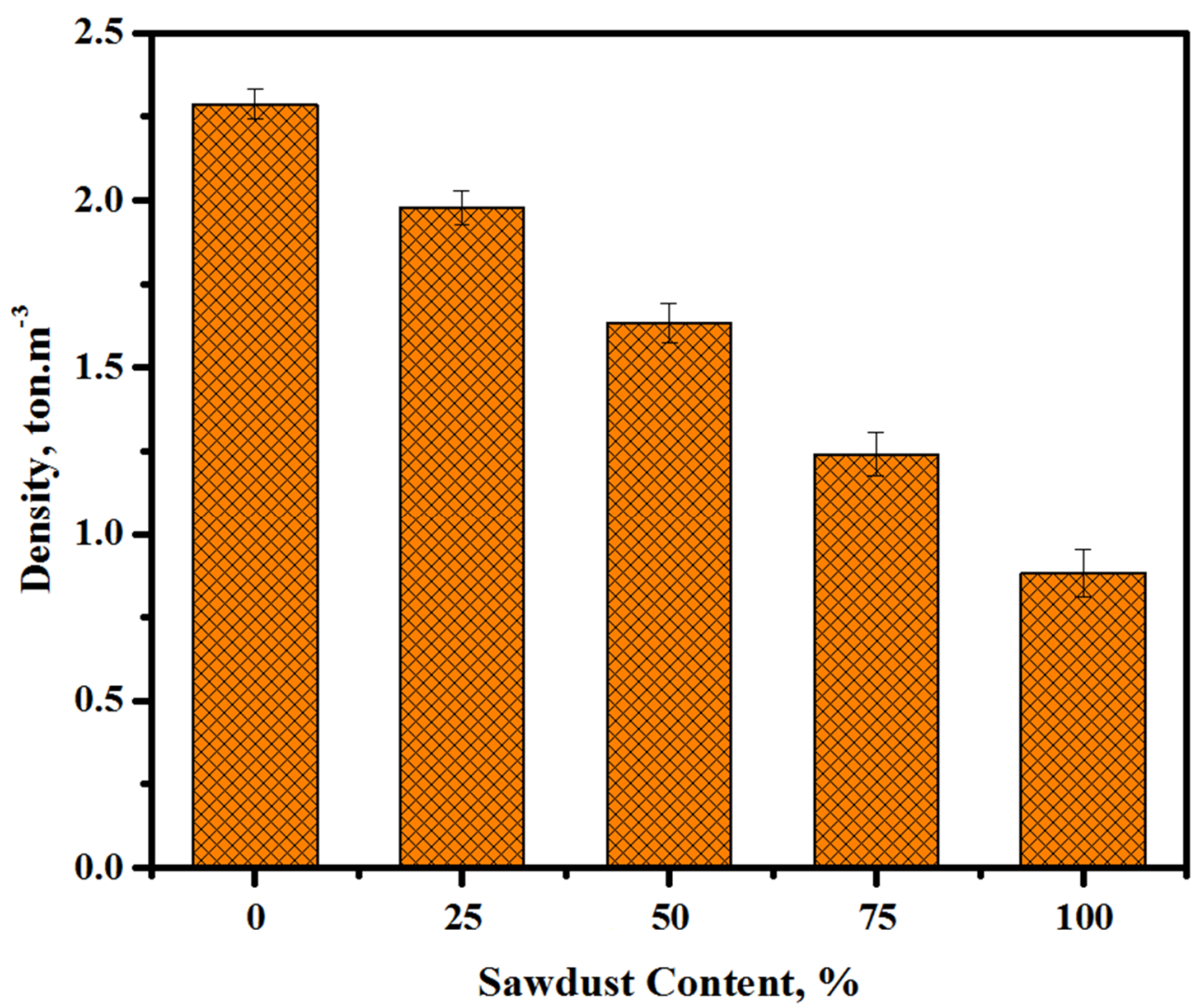

Figure 7. Densities of the prepared concretes with various sawdust contents.

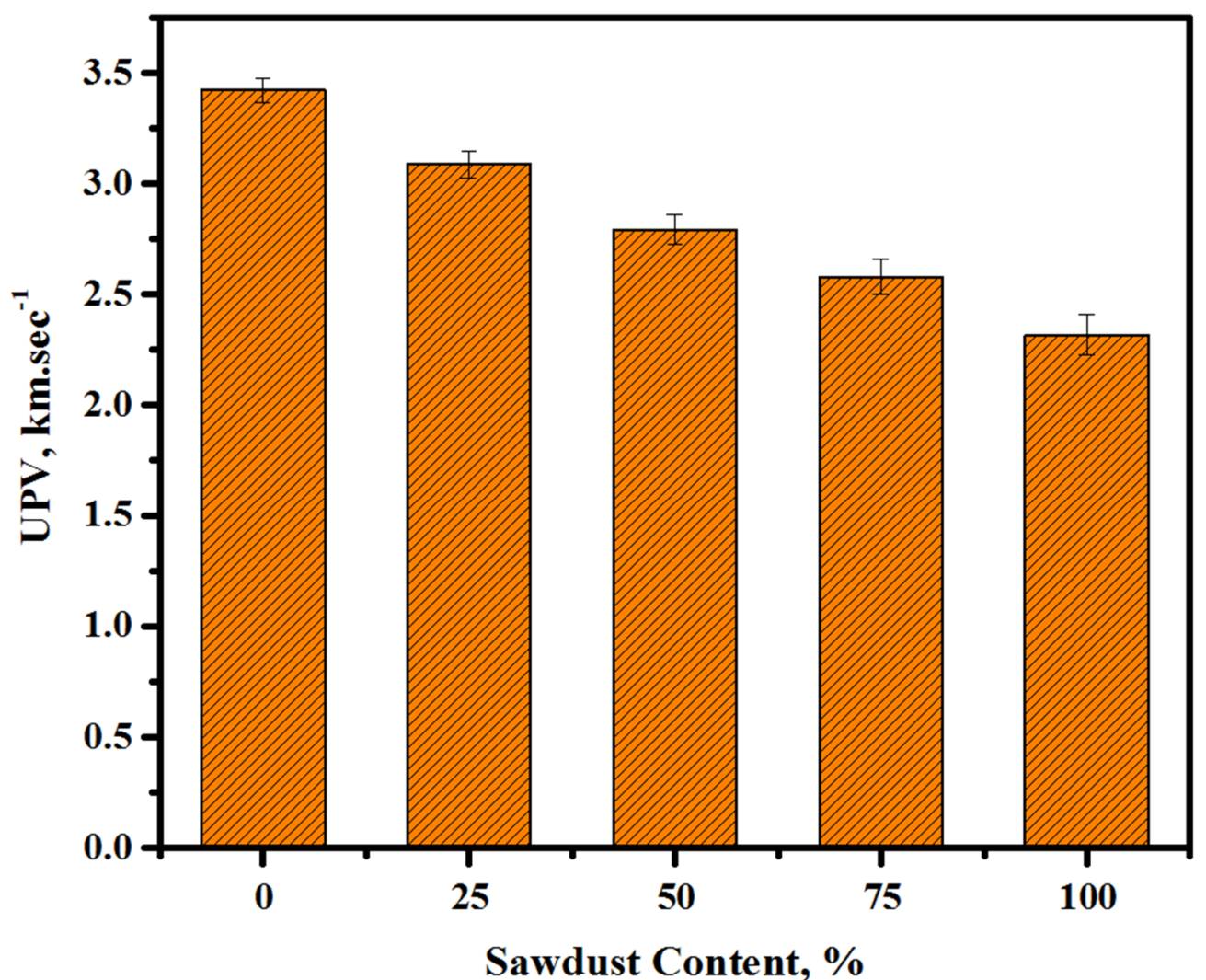

Figure 8. UPV readings of the prepared concretes with various sawdust contents at 28 days of age. 


\subsection{Compressive Strength (CS)}

Figure 9 shows the CS vales of the concretes containing various levels of sawdust as a substitute for sand and gravel aggregates. For each mixture, three samples were examined and the average reading was adopted. The CS of the prepared concrete was measured at the curing age of $1,3,7$, 28,56 , and 90 days. The CS was constantly augmented with the increase in the curing age. At an early age (after $24 \mathrm{~h}$ ), with an increase in the level of replacement of river sand and gravel by sawdust from 0 to $25,50,75$, and $100 \%$, the early strength dropped from 22.6 to $19.4,18.3,17.8$, and $15.2 \mathrm{MPa}$, respectively. Beyond 28 days of the age, a comparable development was seen wherein the CS was decreased from 65.8 to $61.1,55.7,50.4$, and $48.6 \mathrm{MPa}$ with the sawdust contents increased from 0 to $25,50,75$, and $100 \%$, respectively. Analogous behavior was found at the late age of 90 days. where the strength loss percentage was increased with the increase in sawdust levels in the concrete matrix. It was found that the concrete achieved more than $96 \%$ compressive strength at 28 days from the total strength measured at 90 days for all mixtures, and this finding agrees with the previous finding by Ranjbar [22] and Islam [51]. However, it was found that the loss in strength was reduced with time and the percentage of loss with $100 \%$ sawdust dropped from $32.7 \%$ at an early age (1 day) to $26.1 \%$ at an age of 28 days and up. Consequently, the total reduction in CS with an increase in the sawdust content was addressed to three reasons. The first reason was that waste sawdust revealed a higher ability of water absorption than river sand and crushed gravels. Nonetheless, the varied distribution the water mixing with the concretes matrix could weaken the chemical bonds in alkali-activated paste (GBFS + FA) and aggregates. The second reason was that the shape of sawdust partials compared to those of natural aggregates made the bond between the paste and the aggregate weaker and thus there was a reduction in the concrete CS. The third reason was that the existence of organic matter led to a reduction in the aggregate-paste bonds and increased the porosity, thereby affecting the concrete CS. The fourth reason was that the substitution of the stronger substance via the weaker one and the lack of the pozzolanic action by the sawdust waste also affected negatively the strength development. This finding was consistent with the previous reports of Kanojia and Jain, S. [52], Martínez-García et al. [53], and González-Fonteboa et al. [54].

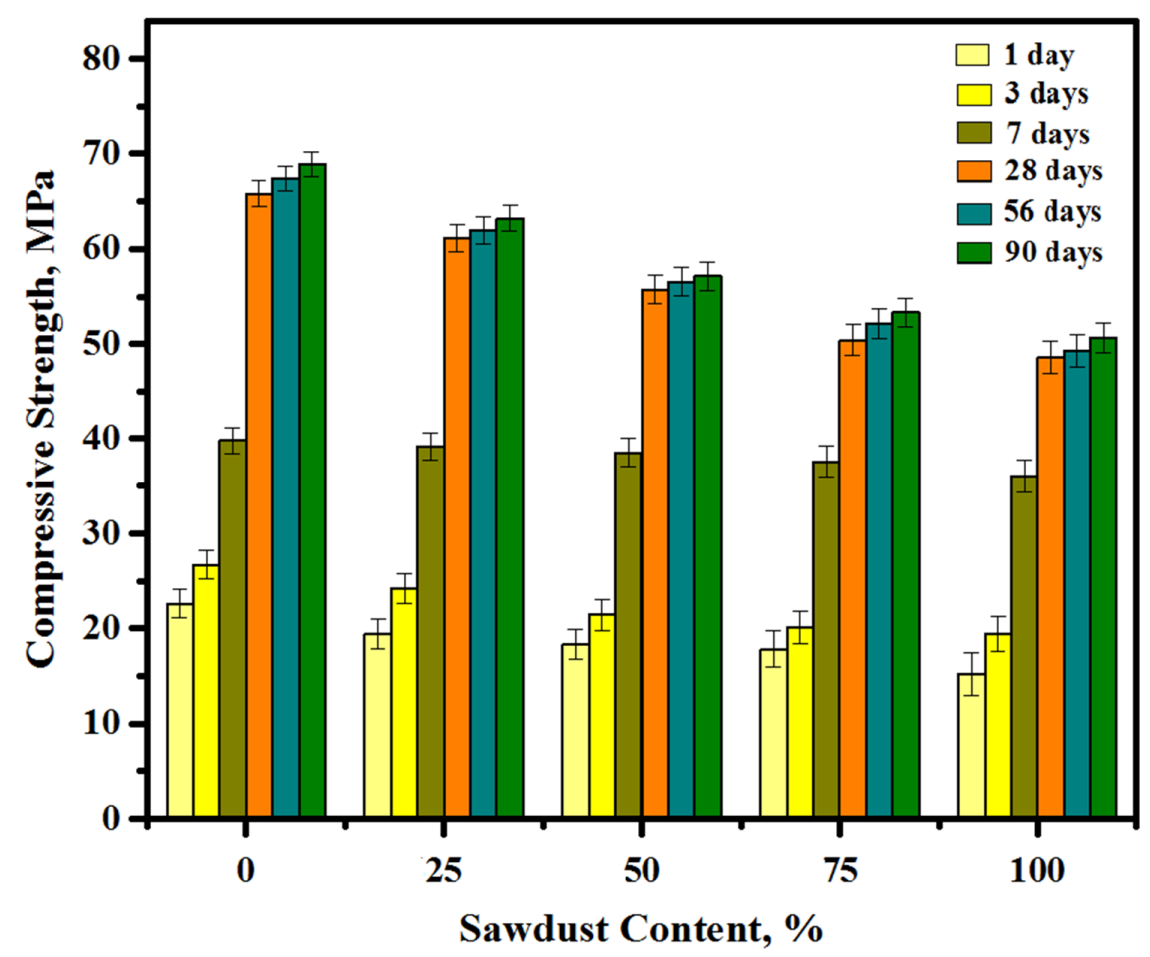

Figure 9. Compressive strength results of the prepared concrete at various sawdust contents. 


\subsection{Flexural and Tensile Strength}

The flexural strength (FS) of the LWCs were measured to evaluate their capacity for resisting the deformation when subjected to load. The FS tests of alkali-activated concretes prepared with various levels of sawdust wastes as a substitute for river sand/crushed gravel aggregates were conducted after curing for 28 days. For every mixture, the mean values of three samples were evaluated, as presented in Figure 10. The prepared specimens' FS changes dramatically with the level of sawdust replacement of natural aggregates. It decreases from around $6.8 \mathrm{MPa}$ at a $0 \%$ content to $6.2,5.7,5.1$, and $4.9 \mathrm{MPa}$ at an increasing level of sawdust to $25,50,75$, and $100 \%$, respectively. In terms of sawdust-based fine and coarse aggregates in alkali-activated lightweight concrete, a $100 \%$ sawdust addition exhibits the highest effects on the FS value and the concrete specimen's loss of more than $27 \%$ flexural strength with a rise in the sawdust level from 0 to $100 \%$. However, the FS for all mixtures achieved an acceptable strength for construction applications.

Figure 11 presented the readings of the splitting tensile strength (STS) of the LWCs obtained with various contents of the sawdust wastes as a substitute for fine/coarse aggregates. The average value of three cylinders' concrete conducted in the evaluation of sawdust inclusion in concrete matrix. For all mixtures, the splitting tensile strength was evaluated at the curing age of 28 days. The loss in the STS was found to increase with the increase in the sawdust content, and the value of strength dropped from 4.2 to 3.9, 3.7, 3.4, and 3.0 MPa with a rise in the sawdust content from 0 to $25,50,75$, and $100 \%$, respectively. Similar to the reasons relating to the loss of strength (Section 3.3), the waster absorption, shape of particles, and organic substance content of sawdust led to a weak bond between the paste and sawdust as an aggregate and presented lower flexural and splitting tensile strengths compared to the control sample prepared with natural aggregates ( $0 \%$ sawdust) [6].

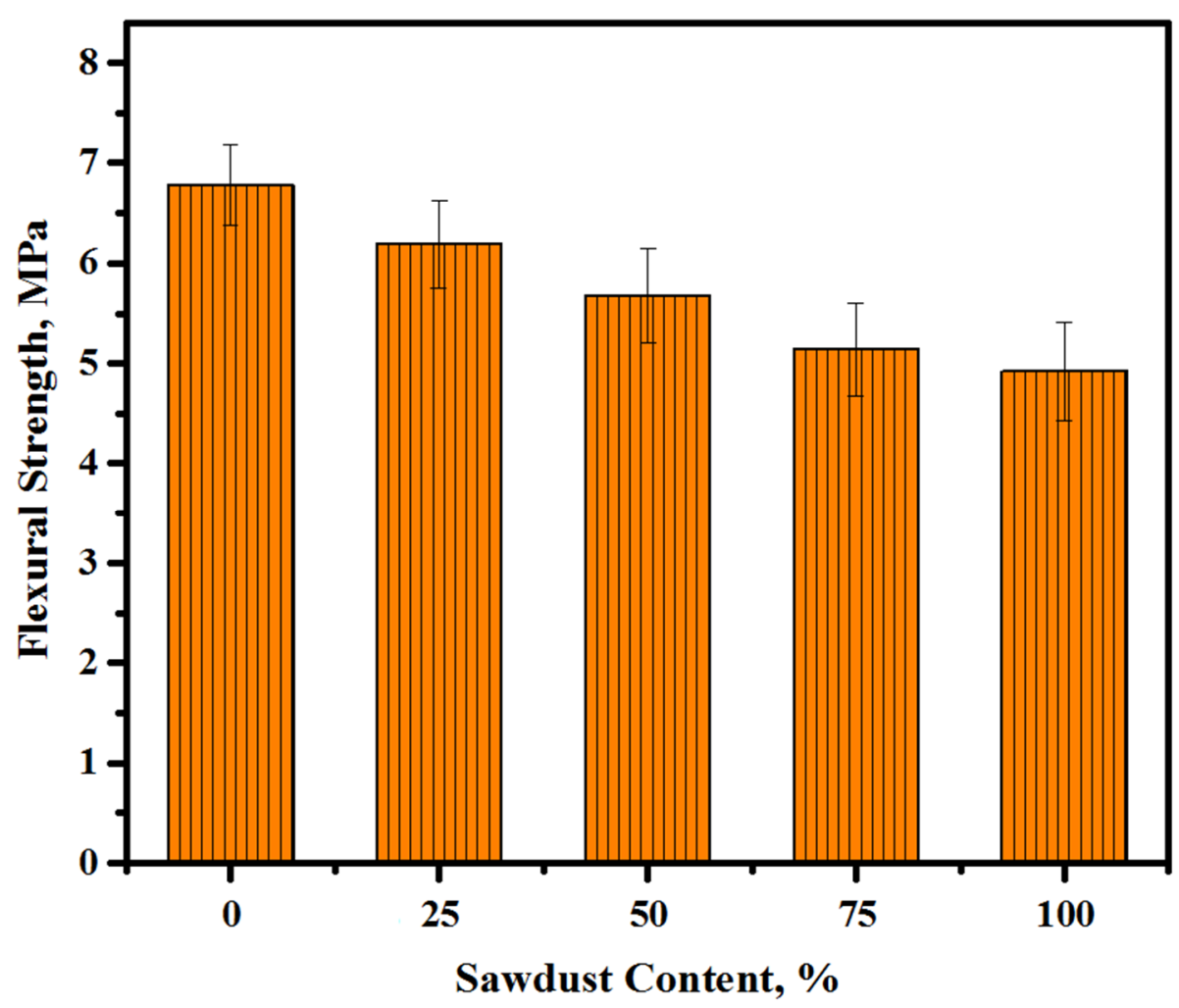

Figure 10. The FS of the prepared LWCs containing various amounts of sawdust. 


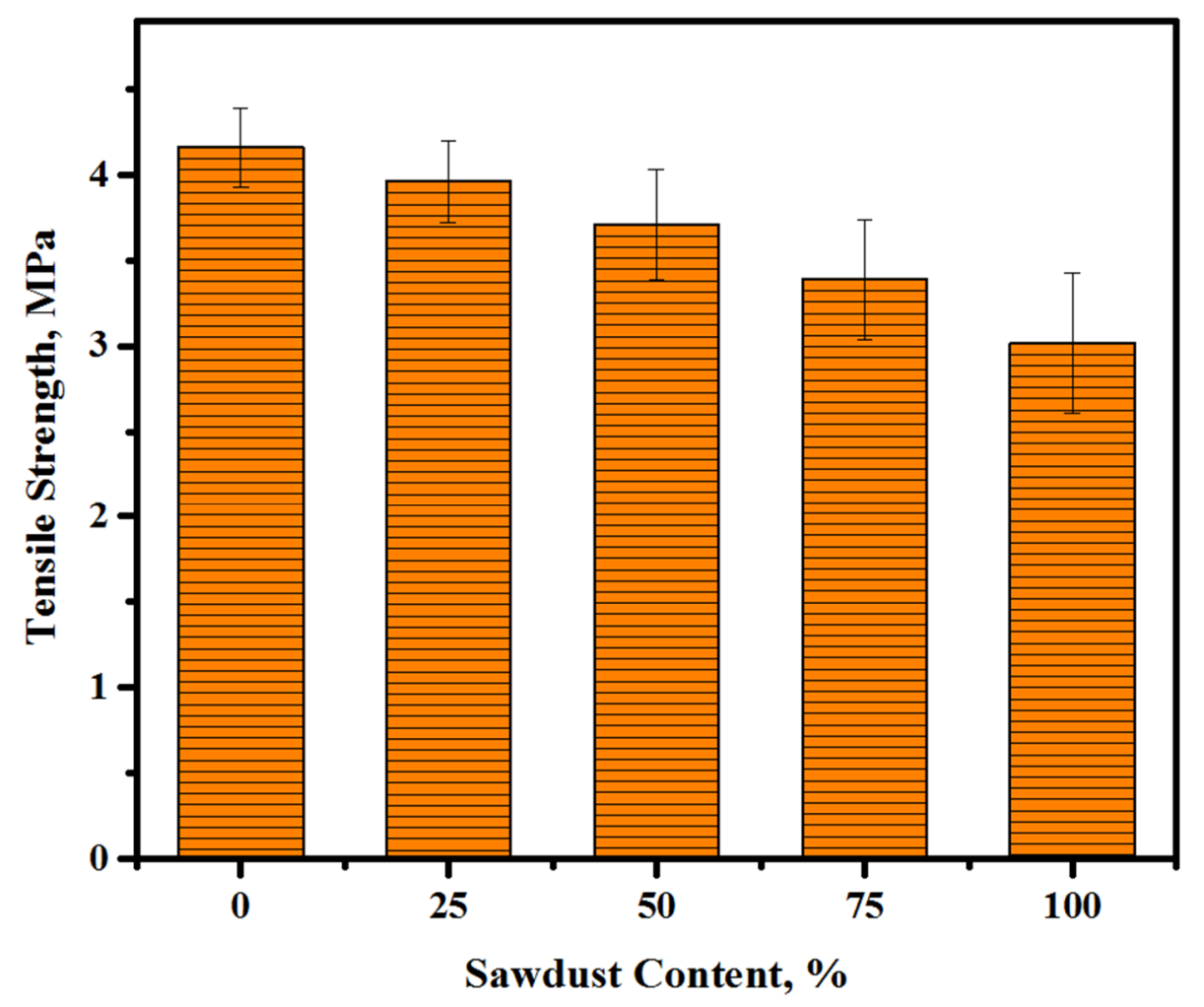

Figure 11. The STS of the LWCs against the sawdust contents.

\subsection{XRD Analysis}

Figure 12 shows the XRD results of the prepared concrete containing various levels of sawdust as well as fine/coarse aggregates as a substitute. Peaks corresponding to the crystalline quartz $\left(\mathrm{SiO}_{2}\right)$, calcium hydroxide $\left(\mathrm{Ca}(\mathrm{OH})_{2}\right)$ and mullite $\left(3 \mathrm{Al}_{2} \mathrm{O}_{3} \cdot 2 \mathrm{SiO}_{2}\right.$ or $\left.2 \mathrm{Al}_{2} \mathrm{O}_{3} \cdot \mathrm{SiO}_{2}\right)$ phases were seen. These phases appeared from FA and GBFS. The intensity of the $\mathrm{Ca}(\mathrm{OH})_{2}$ diffraction peak was decreased with the increase in the sawdust amount from 0 to 25,50,75, and 100\%, where less Portland was generated as well as a higher amount of quartz emerged to be non-reactive with 75 and $100 \%$ of sawdust (Table 5). These were produced from the chemical reaction among the amorphous fractions of FA/GBFS containing minor crystalline phases. The XRD peaks of $\mathrm{OPC}, \mathrm{CaCO}_{3}$, and mullite were evidenced at $28-50^{\circ}$. As the sawdust contents were increased, the intensity of the XRD peak at $50.1^{\circ}$ corresponding to the crystalline quartz phase was increased. The mullite peak at $16^{\circ}$ for $25 \%$ sawdust also showed a lower peak intensity than the control specimen. In addition, the intensities of these peaks revealed a decreasing tendency with the increase in the sawdust contents. The peaks observed at $24^{\circ}$ and $33.8^{\circ}$ were assigned to the Nepheline $\left(\mathrm{Na}_{3} \mathrm{KAl}_{4} \mathrm{Si}_{4} \mathrm{O}_{16}\right)$, where the peak intensity was reduced with the increase in the sawdust levels.

Briefly, the XRD analyses of the prepared LWCs elucidated the influence of $\mathrm{Si}, \mathrm{Al}$, and $\mathrm{Ca}$ on the produced C-(A)-S-H gels and the CS. The XRD results (Table 5) clearly showed that the amount of Portland tended to reduce with an increase in the sawdust level, where the values dropped from 43.1 to $41.3,36.4,18.8$, and $14.9 \%$ with the rise in sawdust levels from 0 to $25,50,75$, and $100 \%$, respectively. An analogous tendency was found with the calcite peak, and all concrete mixtures containing sawdust show a lower amount calcite (1.5-1.1\%) compared to the control sample (2.2\%). It is well known that the OPC amount in the concrete matrix plays a significant role in the production of the C-S-H gel, where a decrease in the OPC level and calcite can lead to weak bonds in the concrete matrix, thereby revealing lower strength values with the increase in sawdust content. Meanwhile, the high absorption and water demand of sawdust directly affected the geopolymerazition and dissolved the silicate and a showed a lower strength [54]. 


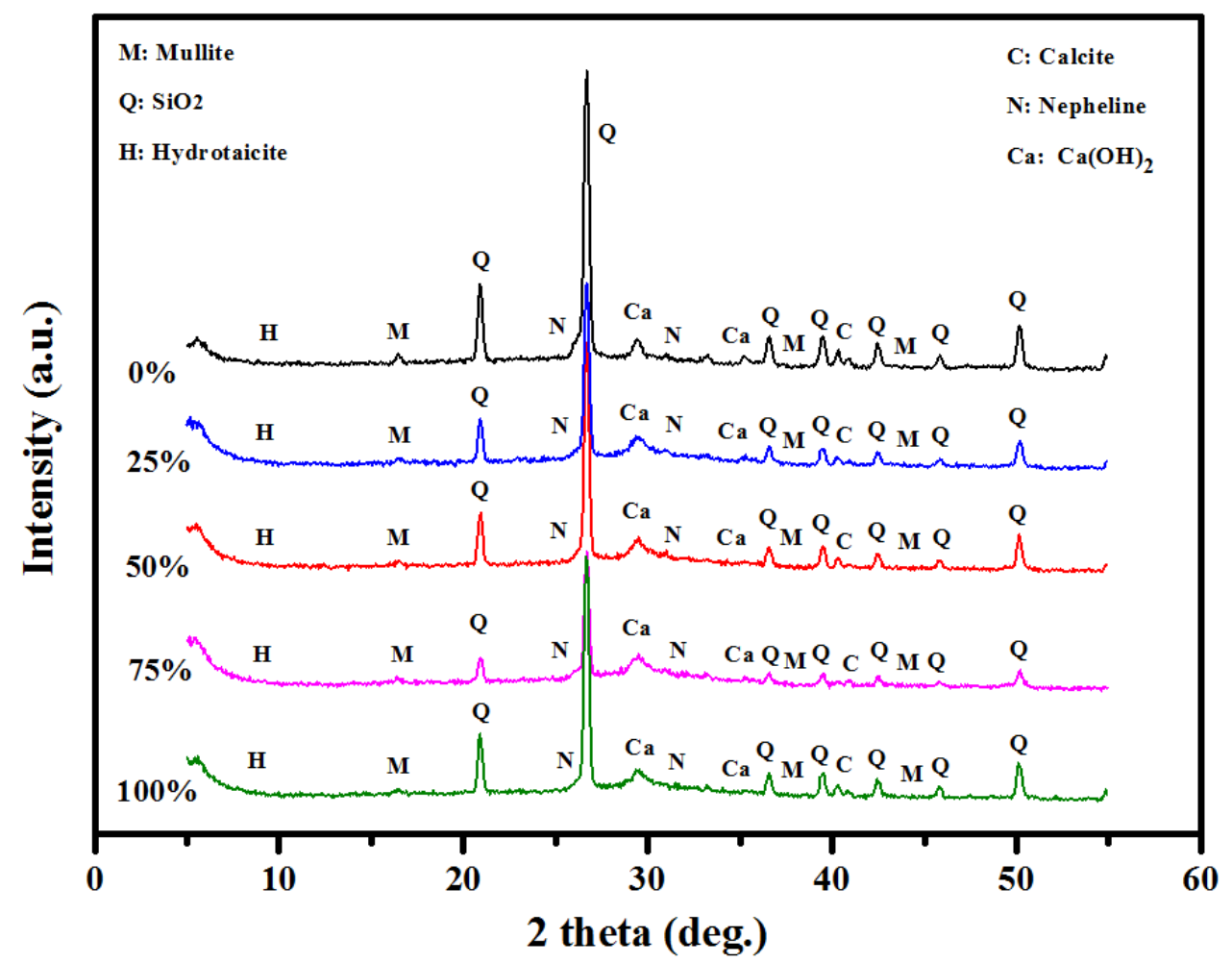

Figure 12. XRD analysis of the prepared concrete with various sawdust contents.

Table 5. XRD peak amount by wt.\%.

\begin{tabular}{cccccc}
\hline \multirow{2}{*}{ Index } & \multicolumn{5}{c}{ Sawdust Content by Vol\% } \\
\cline { 2 - 6 } & $\mathbf{0 \%}$ & $\mathbf{2 5 \%}$ & $\mathbf{5 0 \%}$ & $\mathbf{7 5 \%}$ & $\mathbf{1 0 0 \%}$ \\
\hline${\text { Quartz, } \mathrm{SiO}_{2}}$ & 52.1 & 54.8 & 60.2 & 78.4 & 81.8 \\
Portland, & 43.1 & 41.3 & 36.4 & 18.8 & 14.9 \\
$\mathrm{Ca}(\mathrm{OH})_{2}$ & 2.2 & 1.5 & 1.3 & 1.1 & 1.2 \\
Calcite, $\mathrm{CaCO} \mathrm{Ca}_{3}$ & 2.6 & 2.4 & 2.1 & 1.8 & 2.1 \\
\hline Others & & &
\end{tabular}

\subsection{Predicted Compressive Strength of Proposed Concrete}

ATLAB software was used to develop the proposed ANN model. Specifically, the best neuron number in the hidden layers was found to be fourteen during the iteration process. This result led to achieving the targeted performance of 0.01 related to the learning rate of 0.2. The measured data were divided into three parts-namely, training, testing, and validation. The ANN training with 124 tests was taken into account, while 14 and 23 tests were utilized for the validation and testing steps, receptively. The ANN training proceeded until it minimized the correlation value, in which a correlation value of 0.991 was achieved, as shown in Figure 13a. Whereas, the correlation value of the testing results is 0.9878 (Figure 13b). Moreover, the mean error was considered to evaluate the efficiency of the network during the training and testing steps. In particular, the mean error (M) for the training data was noticed as 1.377, as shown in Table 6 . These indicators values predicted the experimental data well, where the predicted CS was extremely close to the measured one. 

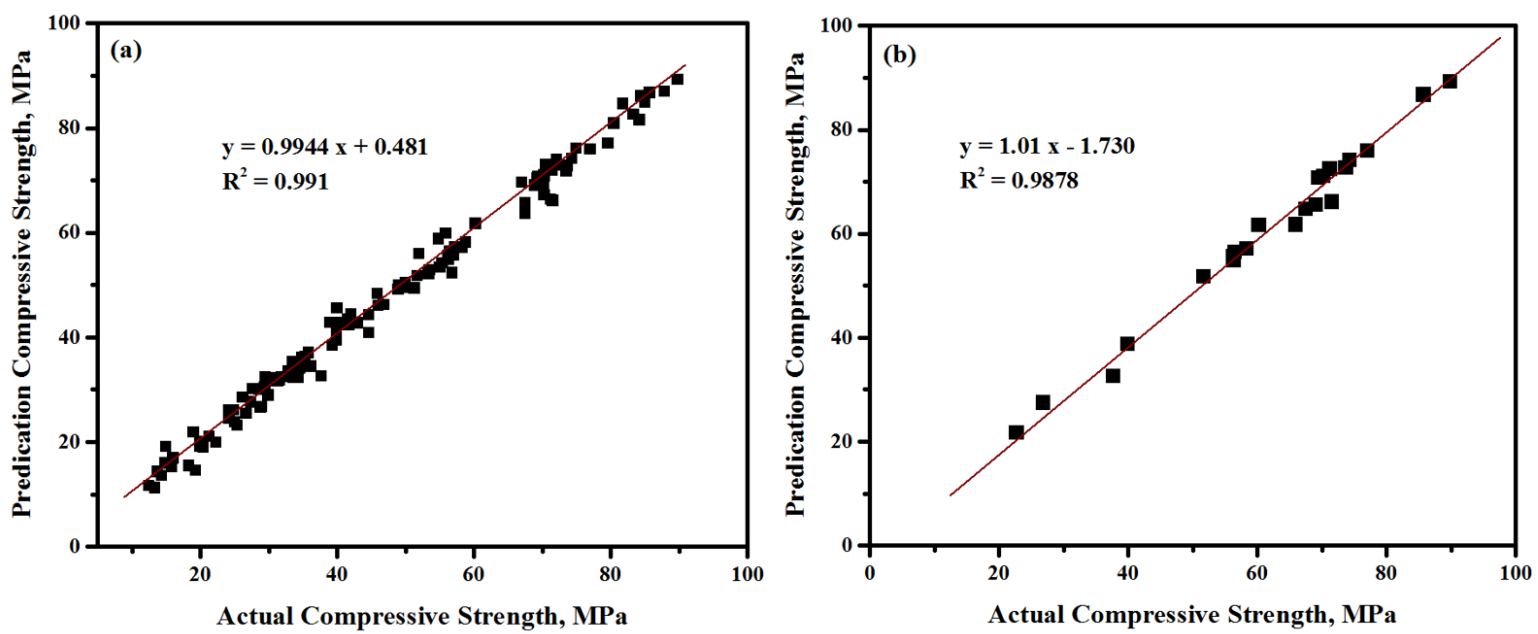

Figure 13. Predicted and measured CS correlation of the proposed LWCs for the (a) training and (b) testing data.

Table 6. The comparison between the experimental data for the testing set and the predicted results from the ANN model.

\begin{tabular}{cccccccccc}
\hline $\begin{array}{c}\text { Experimental } \\
\text { no. }\end{array}$ & $\begin{array}{c}\text { Time } \\
\text { (Day) }\end{array}$ & GBFS/FA & $\begin{array}{c}\text { Solution/ } \\
\text { Binder }\end{array}$ & $\begin{array}{c}\text { Molarity } \\
\mathbf{( M )}\end{array}$ & NS/NH & $\begin{array}{c}\text { Actual } \\
\text { (MPa) }\end{array}$ & $\begin{array}{c}\text { Predicted } \\
\text { (MPa) }\end{array}$ & Error & $\begin{array}{c}\text { Absolute } \\
\text { Error }\end{array}$ \\
\hline 1 & 1 & 30 & 40 & 2 & 0.75 & 22.60 & 21.87 & -0.73 & 0.73 \\
2 & 3 & 30 & 40 & 2 & 0.75 & 26.70 & 27.61 & 0.91 & 0.91 \\
3 & 7 & 30 & 40 & 2 & 0.75 & 39.80 & 38.83 & -0.97 & 0.97 \\
4 & 28 & 30 & 40 & 2 & 0.75 & 65.80 & 61.87 & -3.93 & 3.93 \\
5 & 56 & 30 & 40 & 2 & 0.75 & 67.40 & 64.90 & -2.50 & 2.50 \\
6 & 90 & 30 & 40 & 2 & 0.75 & 68.90 & 65.75 & -3.15 & 3.15 \\
7 & 90 & 40 & 40 & 2 & 0.75 & 73.60 & 72.82 & -0.78 & 0.78 \\
8 & 90 & 60 & 40 & 2 & 0.75 & 85.60 & 87.00 & 1.40 & 1.40 \\
9 & 90 & 70 & 40 & 2 & 0.75 & 89.70 & 89.38 & -0.32 & 0.32 \\
10 & 90 & 20 & 40 & 2 & 0.75 & 56.40 & 56.55 & 0.15 & 0.15 \\
11 & 90 & 30 & 30 & 2 & 0.75 & 37.60 & 32.76 & -4.84 & 4.84 \\
12 & 90 & 30 & 35 & 2 & 0.75 & 56.10 & 55.78 & -0.32 & 0.32 \\
13 & 90 & 30 & 45 & 2 & 0.75 & 60.10 & 61.85 & 1.75 & 1.75 \\
14 & 90 & 30 & 50 & 2 & 0.75 & 56.20 & 55.02 & -1.18 & 1.18 \\
15 & 90 & 30 & 40 & 6 & 0.75 & 74.20 & 74.26 & 0.06 & 0.06 \\
16 & 90 & 30 & 40 & 4 & 0.75 & 71.40 & 66.26 & -5.14 & 5.14 \\
17 & 90 & 30 & 40 & 2.5 & 0.75 & 69.30 & 70.86 & 1.56 & 1.56 \\
18 & 90 & 30 & 40 & 1.5 & 0.75 & 58.20 & 57.22 & -0.98 & 0.98 \\
19 & 90 & 30 & 40 & 2 & 2.5 & 85.60 & 86.86 & 1.26 & 1.26 \\
20 & 90 & 30 & 40 & 2 & 2 & 76.90 & 76.08 & -0.82 & 0.82 \\
21 & 90 & 30 & 40 & 2 & 1.5 & 71.10 & 72.61 & 1.51 & 1.51 \\
22 & 90 & 30 & 40 & 2 & 1 & 70.10 & 71.18 & 1.08 & 1.08 \\
23 & 90 & 30 & 40 & 2 & 0.75 & 51.60 & 51.88 & 0.28 & 0.28 \\
\hline
\end{tabular}

Figure 14 compares the experimental and predicted results against molarity, GBFS to FA ratio, $\mathrm{NS} / \mathrm{NH}$ ratio, solution to binder ratio, and time. The ANN model could realistically predict the actual CS of the alkali-activated concrete. This outcome proved that the ANN model results are consistent with experimental results. In addition, it was inferred the influence of each parameter on the CS of the concrete was clearly seen. For example, Figure 14a clearly shows the dependence of the amount of alkali-activated concrete strength enhancement on increased urea concentration. Both the experimental and predicted results shows a high degree of similarity. The enhancement of concrete strength is gradually increased with the increase in molarity. However, beyond a molarity value of 2 , a not significant concrete strength enhancement is observed compared to the cost effect. As such. 
the molarity of 2 was kept and considered as 2 for further works. Similarly, with an increase in the $\mathrm{NS} / \mathrm{NH}$, the strength improved, as shown in Figure 14b. In the same regard, the contribution of fly ash concentration to the concrete strength enhancement was not significant, as shown in Figure 14c. In contrast, with the increase in the GBFS to FA ratio, the CS of the LWCs was improved. The optimum improvement of strength was achieved at an NS/NH ratio of 70/30. In a similar manner, the optimum value of the solution to binder ratio was 0.4 (Figure 14d).
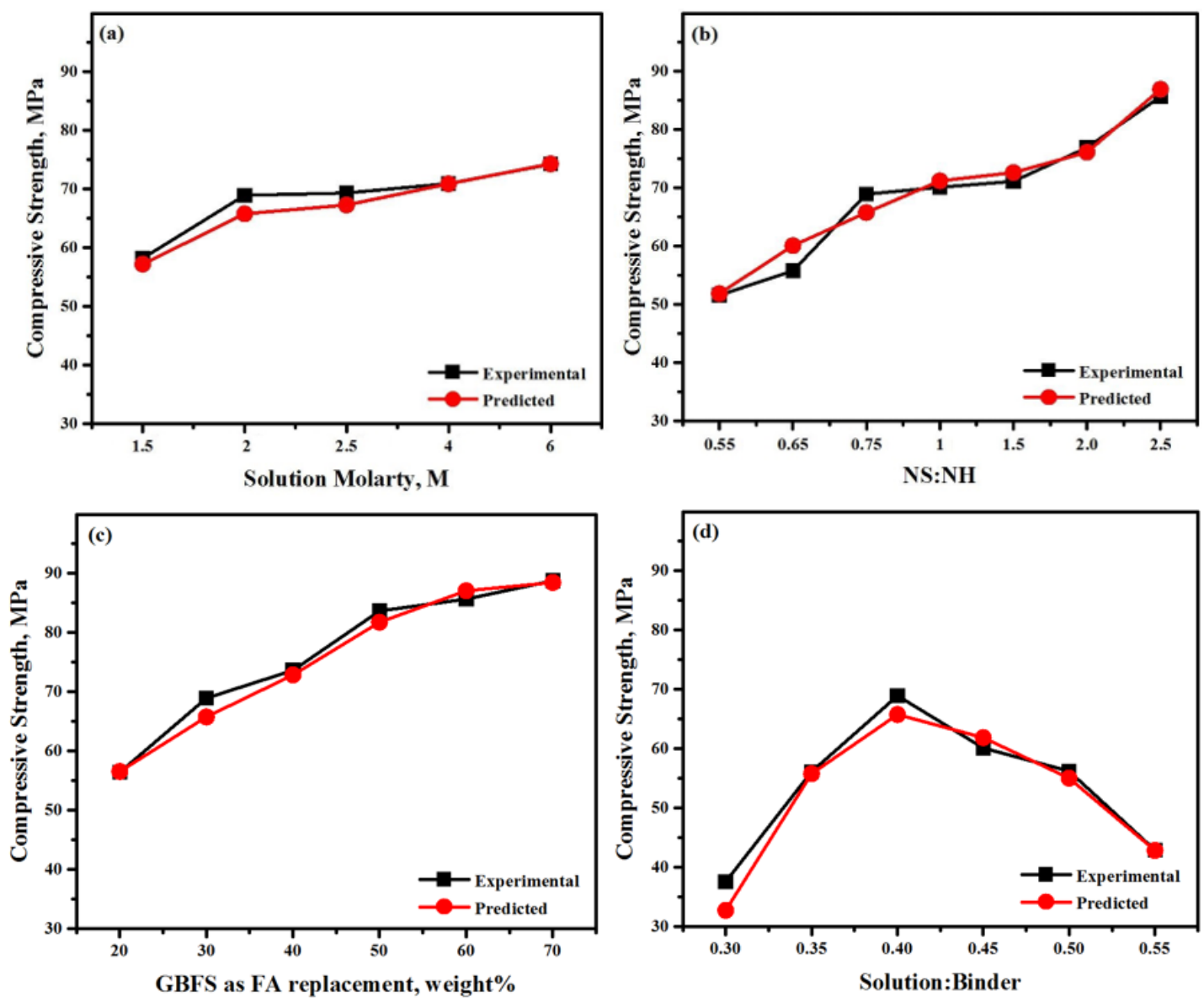

Figure 14. Predicted and actual evolution of alkali-activated strength as a function of (a) molarity, (b) NS/NH, (c) FA/GBFS, (d) and solution to binder ratio.

\subsection{Water Absorption (WA)}

Figure 15 displays the effect of waste sawdust on the WA capacity of the alkali-activated concrete mixes at the curing age of 28 days. The WA of the specimens was elevated as the content of sawdust was increased in the concrete matrix. An increasing sawdust level from 0 to 25,50,75, and 100\% as a substitute for natural aggregates could improve the WA by $9.7,10.1,13.4,15.2$, and $16.9 \%$, respectively. At each level of sawdust replacement, the outcome of WA was affected considerably by the sawdust to river sand/crushed gravel ratio. At a $25 \%$ sawdust level, the water absorption was increased by $4.1 \%$ and this ratio increased with an increasing sawdust replacement and was recorded as more than $74 \%$ with $100 \%$ sawdust. As discussed in Section 3.3, with the rising contents of the sawdust the water demand was increased, thereby increasing the quantity of non-reacted silica and the structural porosity. Concretes containing higher amounts of sawdust showed an improved WA, which was due to the gel formation within the binder matrix. Ahmed et al. [6] attributed the high WA of concrete containing waste sawdust to its porosity and the presence of continuous channels. The other reason for such an enhanced WA ability may primarily be because of the availability of a high amount of free water that formed capillaries in concretes made from bottom ash, as demonstrated by Andrade et al. [55]. 


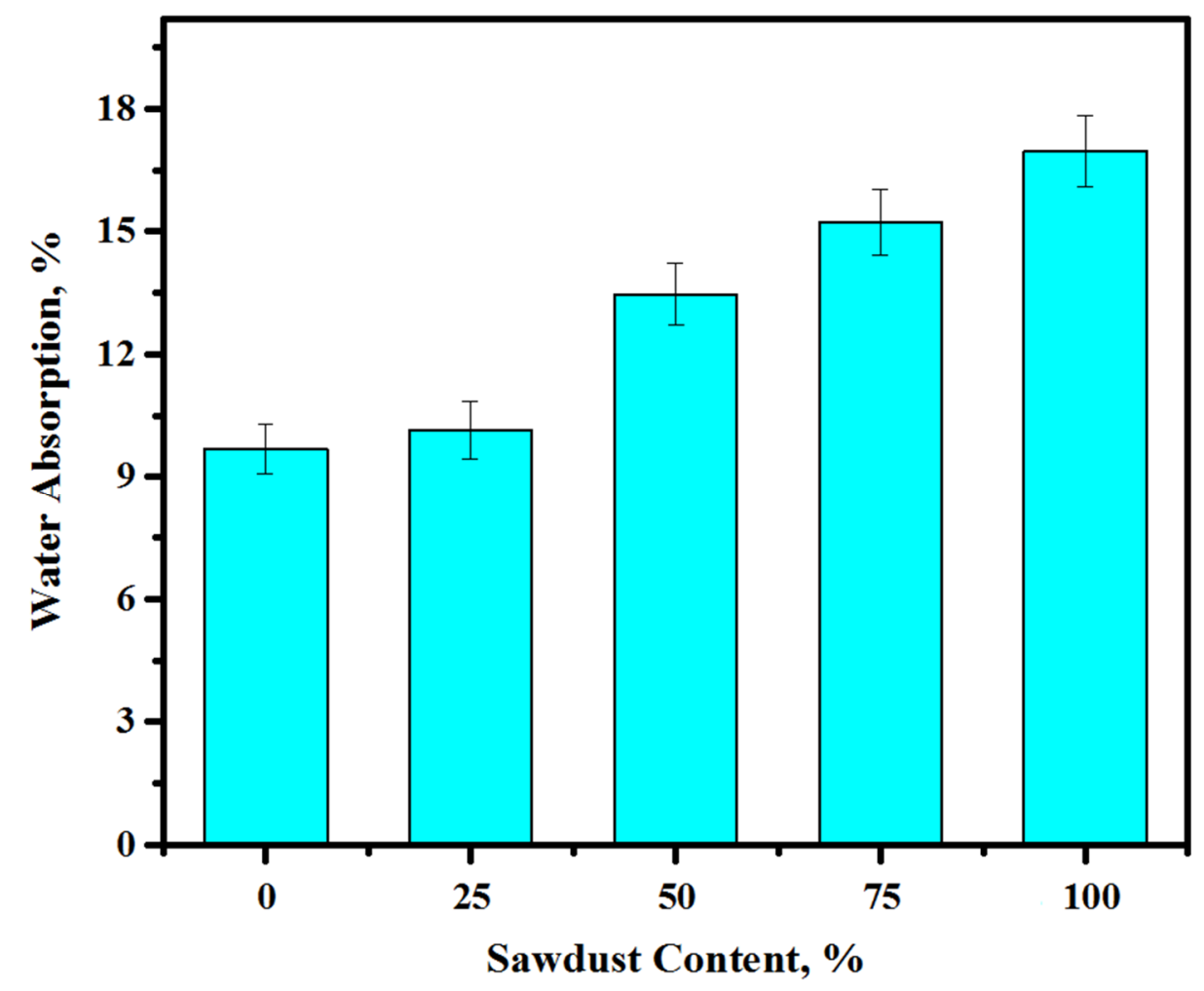

Figure 15. The water absorption of the prepared concrete against different sawdust contents.

\subsection{Drying Shrinkage (DS)}

Figure 16 illustrates the test age-dependent variation in the DS values of alkali-activated concrete prepared using different levels of sawdust as a substitute for natural aggregates. The DS readings was taken at $3,7,14,21,28,56$, and 90 days and it was found that the value of DS for all samples was improved with the increase in the curing ages. The inclusion of sawdust waste into the alkali-activated concretes could in fact enhance the DS values, particularly at early ages. Furthermore, the values of DS were reduced with the rise in the sawdust levels, which was due to the specialty of the sawdust's microstructures. For all the prepared concrete mixtures, it was observed that the increment in the drying shrinkage reduced with time; after 7 days of curing age, a more than $40 \%$ increment in the reading of drying shrinkage was recorded compared to the results of 3 days. However, this percentage was reduced with time and less than $6 \%$ and $2 \%$ were recorded after 28 and 90 days, respectively. At the early age of 3 days, the addition of sawdust as a natural aggregate replacement contributed to reducing the drying shrinkage by $2.1,3.7,6.2$, and $7.1 \%$ with $25,50,75$, and $100 \%$, respectively. A comparable tendency was found after the curing age of 28 days, and the inclusion of sawdust showed more efficiency in reducing the shrinkage value by $3.5,4.8,7.1$, and $7.6 \%$, respectively with $25,50,75$, and $100 \%$ compared to the control sample. The observed reduction in the DS of sawdust was ascribed to the inner curing effects of sawdust, providing some extra moisture and thus improvement in the DS response of the resulting mixes [56]. Actually, sawdust channels played a vital role by retaining water inside the alkaline solution-activated matrix, which in turn rendered the compensation of the essential moisture contents for the concrete matrix, leading to DS deformation afterward. Comparable results were obtained by Juarez et al. [57] and Tong et al. [58] on fiber-blended cement-based systems. 


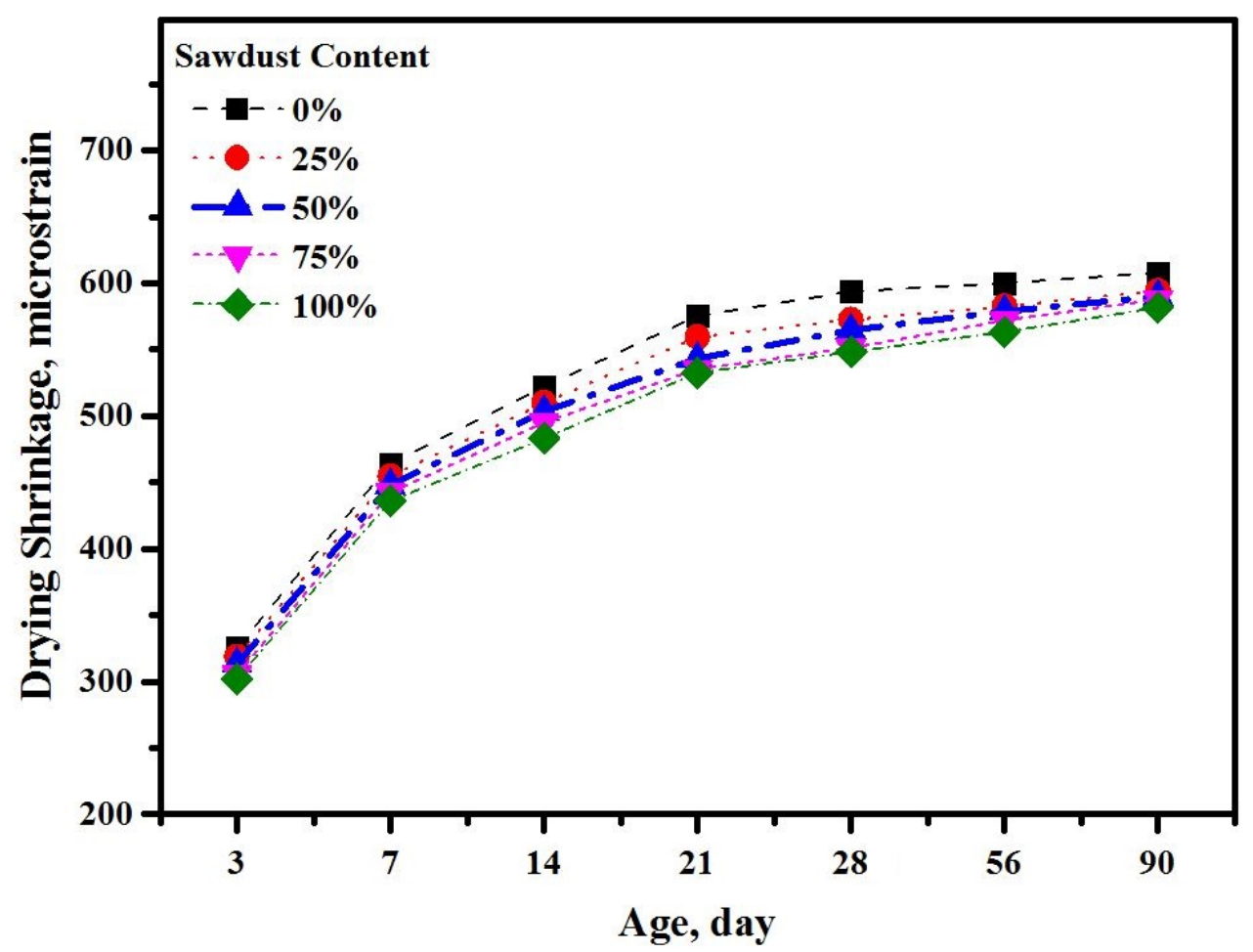

Figure 16. Drying shrinkage of the prepared concrete with various sawdust contents.

\subsection{Sound Absorption}

The acoustic absorption coefficients characterize the capacity of materials to absorb sound energy. Figure 17 shows the effect of the sawdust waste content on the measured sound absorption of the proposed concrete. All the specimens were tested under a frequency between 0 and $5000 \mathrm{~Hz}$. In general, the tested specimens showed a better performance under frequency in a range between 500 and $3000 \mathrm{~Hz}$ and tended to absorb a higher amount of sound energy. The acoustic properties of the proposed concretes were improved with the inclusion of sawdust waste. The sound absorption coefficients tended to increase from 0.43 to 0.74 with the increase in the sawdust substitution levels from $0 \%$ to $100 \%$, respectively. Figure 18 illustrates the noise reduction coefficient of the LWCs prepared with different amounts of sawdust wastes as a natural aggregate replacement. The results indicated that the rising level of sawdust waste substitution from $0 \%$ to $100 \%$ led to enhancing the acoustic properties of the concrete and increased the noise reduction coefficient from 0.124 to 0.237 , respectively (Table 7). Several factors are responsible for the improved acoustic absorption performance. The increasing amount of sawdust wastes created more interconnecting voids at varied length scales within the alkali-activated concrete matrix and thus enhanced the noise reduction coefficients [59-62]. These porous materials showed an improved sound absorption in the high-frequency region, indicating a shift in the sound absorption frequency towards higher values with the increase in the sawdust content in the concrete. The observed decrease in the concrete density caused the frequency to shift towards higher values. In fact, sawdust, being a highly porous substance, can enhance the porosity of alkali-activated pastes when incorporated into the concrete matrix. The enhancement of the noise reduction coefficient with the addition of the sawdust aggregates was due to the air content and porosity increase in the concrete prepared with higher concentrations of sawdust aggregate. In previous studies [62,63], it was found that the sound absorption highly influenced the porosity and density of materials, and the noise reduction coefficient tended to increase with a decrease in the density of materials. The sound absorption of the porous materials is due to the energy loss by the friction generated in the walls of porous structures [64]. Consequently, the concrete specimen with a fraction of the voids generally showed higher values of sound absorption coefficients in the entire frequency domain [65]. 
Table 7. Effect of the sawdust content on the noise reduction coefficient (NRC).

\begin{tabular}{cccccc}
\hline Frequency $\mathbf{( H z )}$ & $\mathbf{0 \%}$ & $\mathbf{2 5 \%}$ & $\mathbf{5 0} \%$ & $\mathbf{7 5 \%}$ & $\mathbf{1 0 0} \%$ \\
\hline 250 & 0.040087632 & 0.053833563 & 0.046065998 & 0.03238883 & 0.082436911 \\
500 & 0.050464286 & 0.072491523 & 0.060480702 & 0.047957295 & 0.038381466 \\
1000 & 0.105207679 & 0.241543934 & 0.159514703 & 0.320905945 & 0.156701336 \\
2000 & 0.301440476 & 0.176171063 & 0.308779167 & 0.20956316 & 0.673137931 \\
NRC & 0.124300018 & 0.136010021 & 0.143710142 & 0.152703808 & 0.237664411 \\
\hline
\end{tabular}

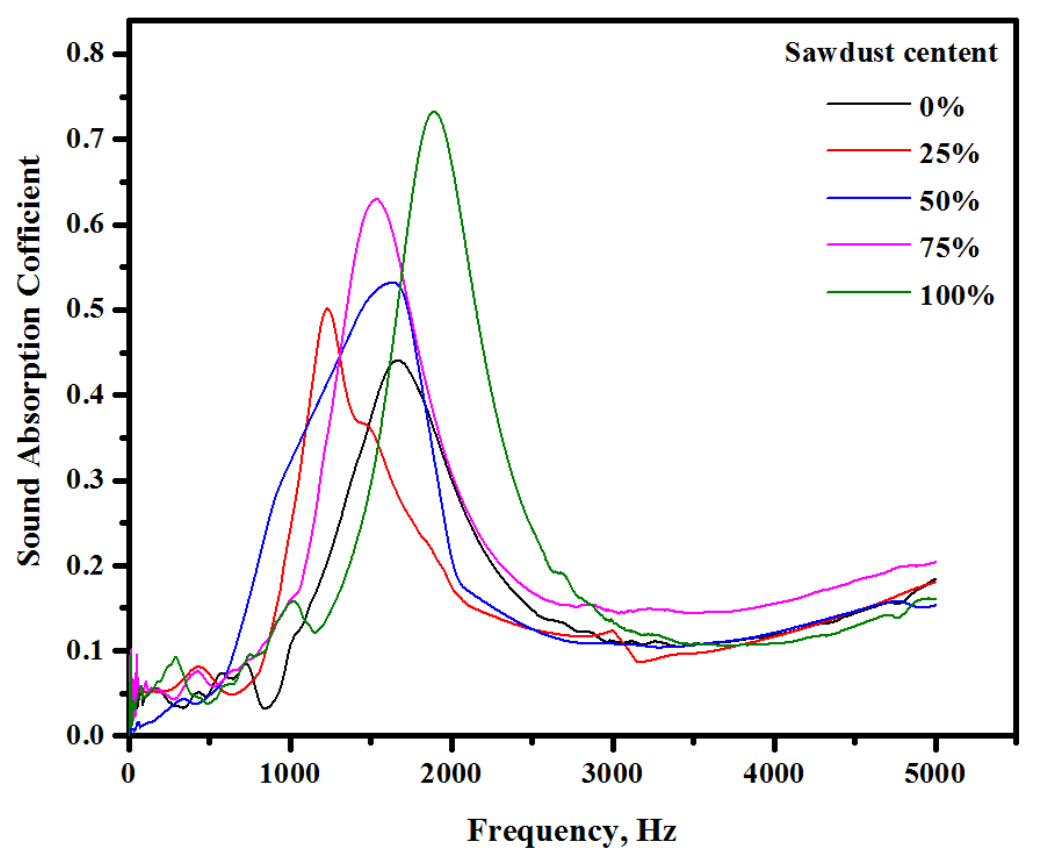

Figure 17. Sound absorption coefficients of the concretes prepared with different amounts of sawdust wastes.

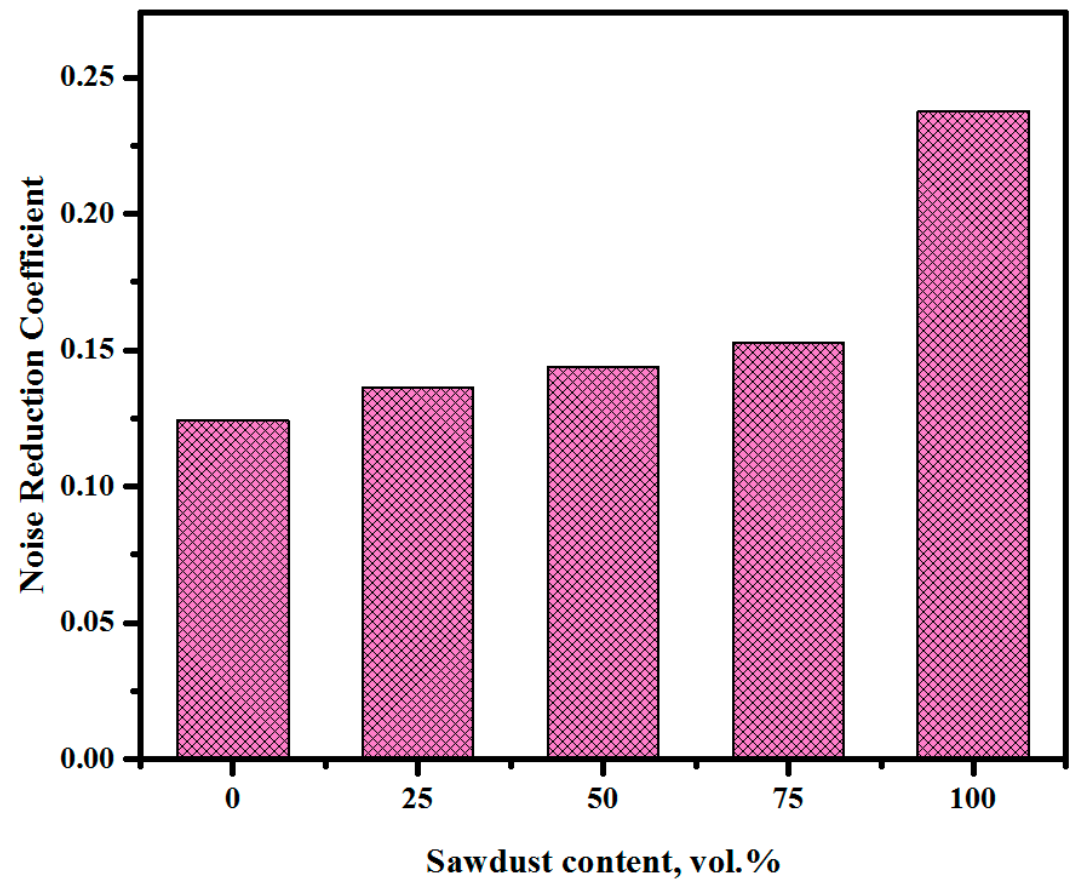

Figure 18. Effects of the sawdust contents on the noise reduction coefficient of the proposed alkali-activated concretes. 


\subsection{Thermal Conductivity}

Generally, alkali-activated LWCs are used in building partitioning. Thus, it is important to evaluate their thermal characteristics when applied in the external walls. Two methods were used to assess the thermal properties of the proposed concretes. First, the influence of the sawdust inclusion on the thermal conductivity of the concretes was measured by calculating the time of heat transfer at 28 days of curing age (Figure 19). The test results of thermal conductivity for the control and sawdust concretes showed a decrease with the rise in sawdust levels as a partial substitution for fine/coarse aggregates. The sample made with highest sawdust content $(100 \%)$ showed the maximum time for heat transfer (188 $\mathrm{min}$ ) compared to the control specimen ( $0 \%$ sawdust), which was only $36 \mathrm{~min}$, while the other three mixtures containing 25,50 , and $75 \%$ sawdust displayed 61-, 108-, and 149-minute increases in heat transfer time, respectively. Second, the obtained values of the thermal conductivity coefficient were used to evaluate the thermal characteristics of the suggested lightweight concrete. The results presented in Figure 20 make it clear that the increasing sawdust content as a natural aggregate replacement resulted in an enhancement in the thermal properties of the proposed concrete. For all the tested specimens, the value of the thermal conductivity coefficient trend to decrease with the increasing sawdust waste content. It was found the thermal conductivity coefficient $\mathrm{k}$-value dropped from 0.39 to $0.24,0.19,0.13$, and $0.09 \mathrm{~W} / \mathrm{m} . \mathrm{K}$ with an increasing level of replacement from 0 to $25,50,75$, and $100 \%$, respectively. In study by Liu et al. [65], it was reported that the enhancement in thermal properties tended to increase with an increase in the porosity of specimens and a reduction in the density. This indicated that the inclusion of sawdust waste led to a reduction in the density of the proposed concrete as well as an increase in the total porosity, thereby lowering the thermal conductivity. Because of its light weight and porosity, sawdust with a low density can reduce the thermal conductivity of formulated concretes. It was acknowledged that [66] this decrease in the thermal conductivity may be related to the convection process, wherein the pore density, distribution, and geometry within the concrete matrix play a significant role. Figure 21 shows the thermal conductivity and density correlation of all the prepared concretes with the obtained correlation coefficient of 0.9048 . The lightweight aggregates concretes are known to reveal a tendency of decreasing density, resulting in more porosity and hence a reduction in the thermal conductivity $[67,68]$.

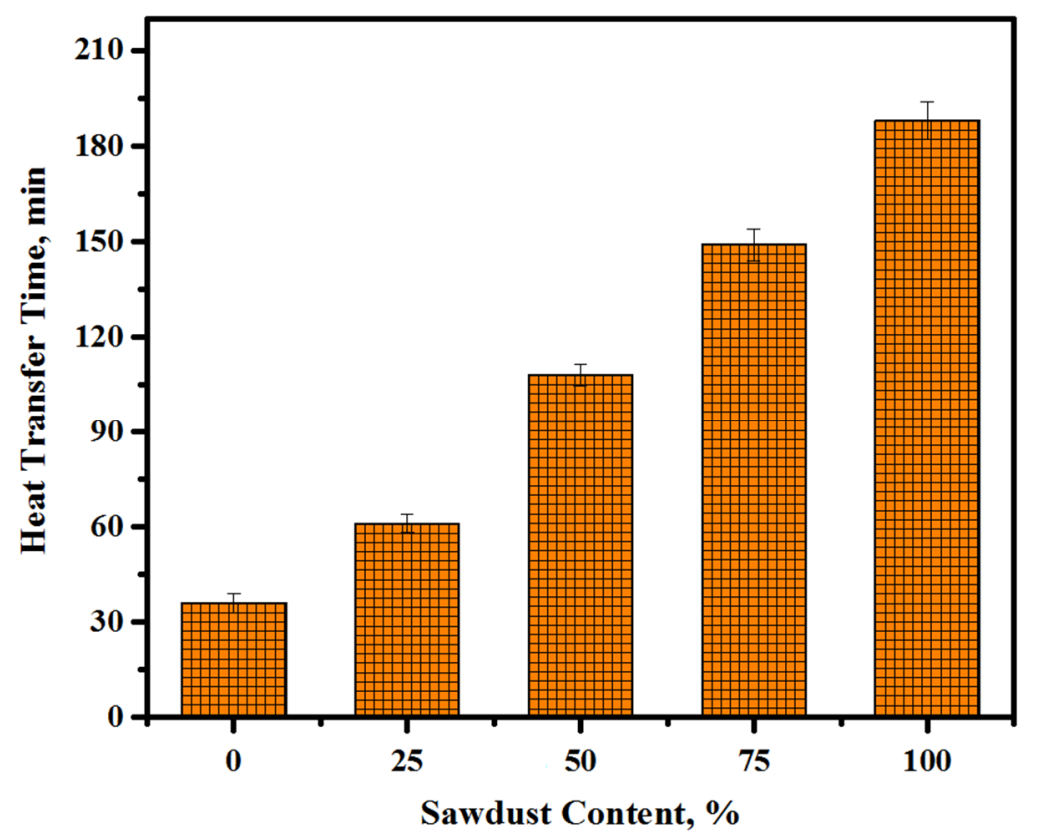

Figure 19. Thermal conductivity of the prepared concrete at various sawdust contents. 


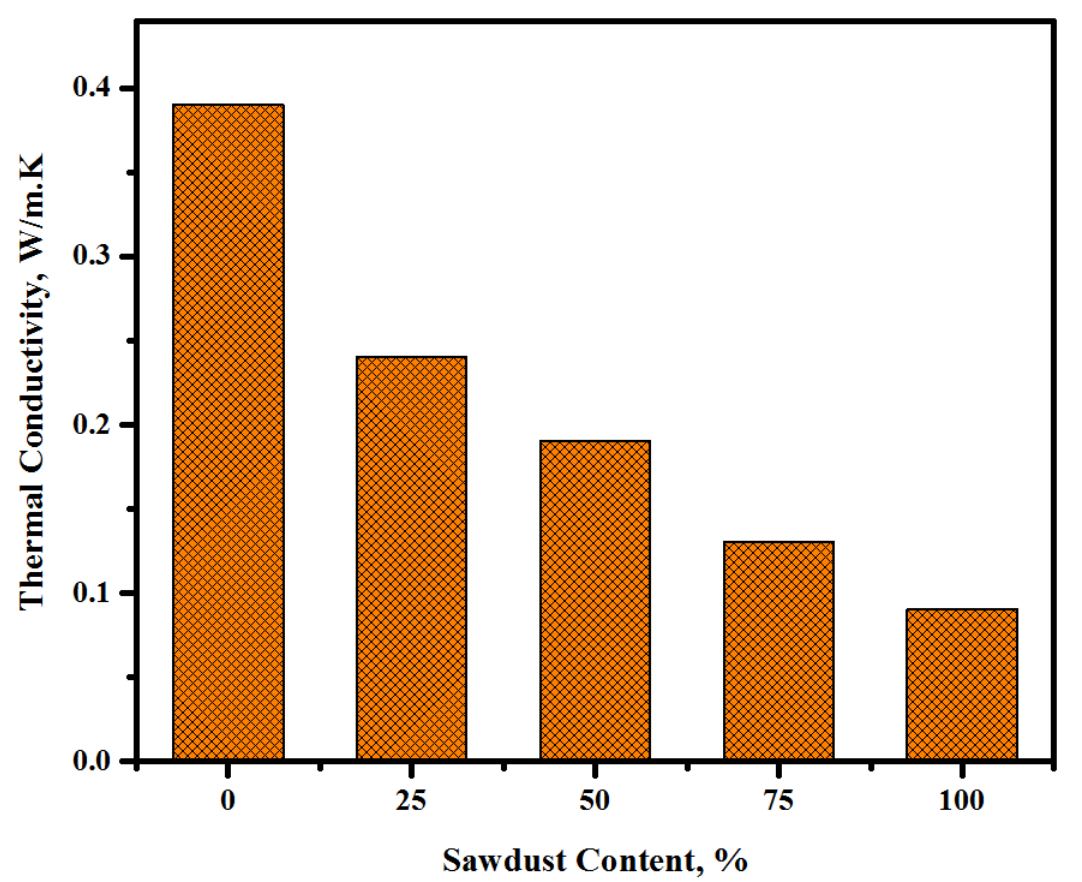

Figure 20. Thermal conductivity coefficients of the prepared concretes at various sawdust contents.

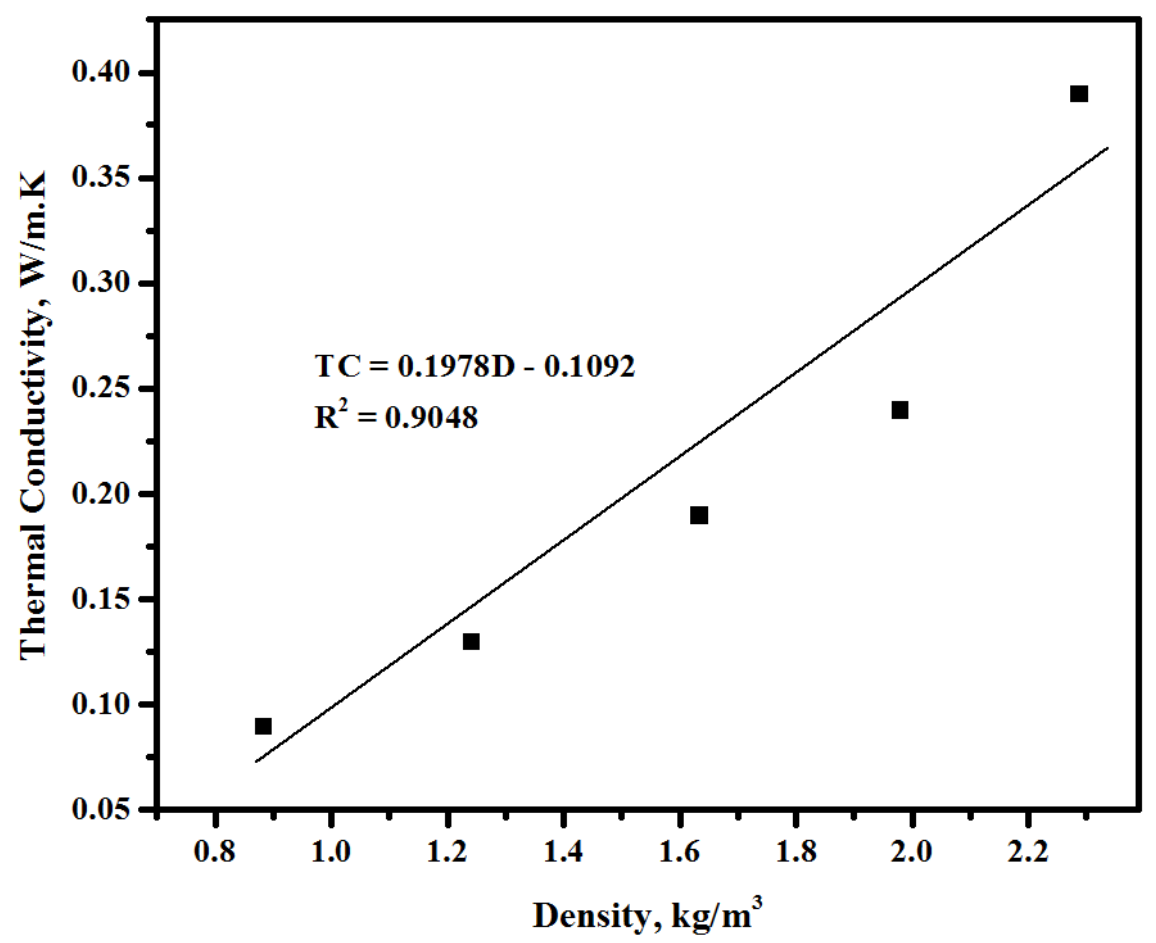

Figure 21. Relationship between the heat transfer time and the density of the prepared concretes.

\subsection{Environmental and Economic Benefits}

The total $\mathrm{CO}_{2}$ release, cost, and energy utilization of natural aggregates, including river sand, crushed gravel, and fine and coarse sawdust, were calculated to determine the life cycle of every material (Table 4 in Section 3.7). The results indicated that the river sand and crushed gravel required a higher amount of diesel during the synthesis than sawdust waste, leading to a rise in the $\mathrm{CO}_{2}$ release, cost, and energy usage. Natural aggregates consumed a higher amount of energy in the range of $0.134-0.148 \mathrm{GJ} / \mathrm{m}^{3}$ compared to fine $\left(0.018 \mathrm{GJ} / \mathrm{m}^{3}\right)$ and coarse $\left(0.021 \mathrm{GJ} / \mathrm{m}^{3}\right)$ sawdust. This showed direct 
proportionality to the energy expenditure, $\mathrm{CO}_{2}$ release, and enlarged outlay of natural aggregates. It revealed a higher carbon dioxide release $\left(0.012\right.$ tonne $\left./ \mathrm{m}^{3}\right)$ than sawdust $(0.0008$ tonne/tonne). Similar to the $\mathrm{CO}_{2}$ release, the cost involvement for river sand and crushed gravel were the highest from sawdust. This was mainly because of the collection and preparation stages, such as crushing and sieving, as well as the longer transportation distance. This, in turn, raised the cost of river sand and crushed gravel to 55 and $65 \mathrm{RM} / \mathrm{m}^{3}$ compared to the respective fine and coarse sawdust cost of 34.5 and $36 \mathrm{RM} / \mathrm{m}^{3}$. The replacement of natural aggregates by lightweight fine and coarse sawdust in the alkaline-activated matrix was shown to be essential to attain the sustainability conditions such as lower $\mathrm{CO}_{2}$ release, cost, and energy utilization.

Figure 22 depicts the carbon dioxide emissions of the prepared concretes against different contents of sawdust. The impact of the sawdust substitution for river sand and crushed aggregates on the $\mathrm{CO}_{2}$ release of the lightweight alkaline solution-activated concretes was studied. The $\mathrm{CO}_{2}$ release was observed to drop from 10.9 to $8.3,5.8,3.3$, and $0.8 \mathrm{~kg} / \mathrm{m}^{3}$ with the rise in the sawdust contents from 0 to $25,50,75$, and $100 \%$, respectively. The alkaline solution-activated concrete matrix containing $100 \%$ sawdust $\left(1 \mathrm{~kg} / \mathrm{m}^{3}\right)$ could reduce the $\mathrm{CO}_{2}$ release by $90 \%$ compared to $10.9 \mathrm{~kg} / \mathrm{m}^{3}$ for natural aggregates. This lowering in the $\mathrm{CO}_{2}$ release from alkaline solution-activated concretes containing sawdust as an alternative to natural aggregates affirmed the possibility of making a simple sustainable development in the construction sector.

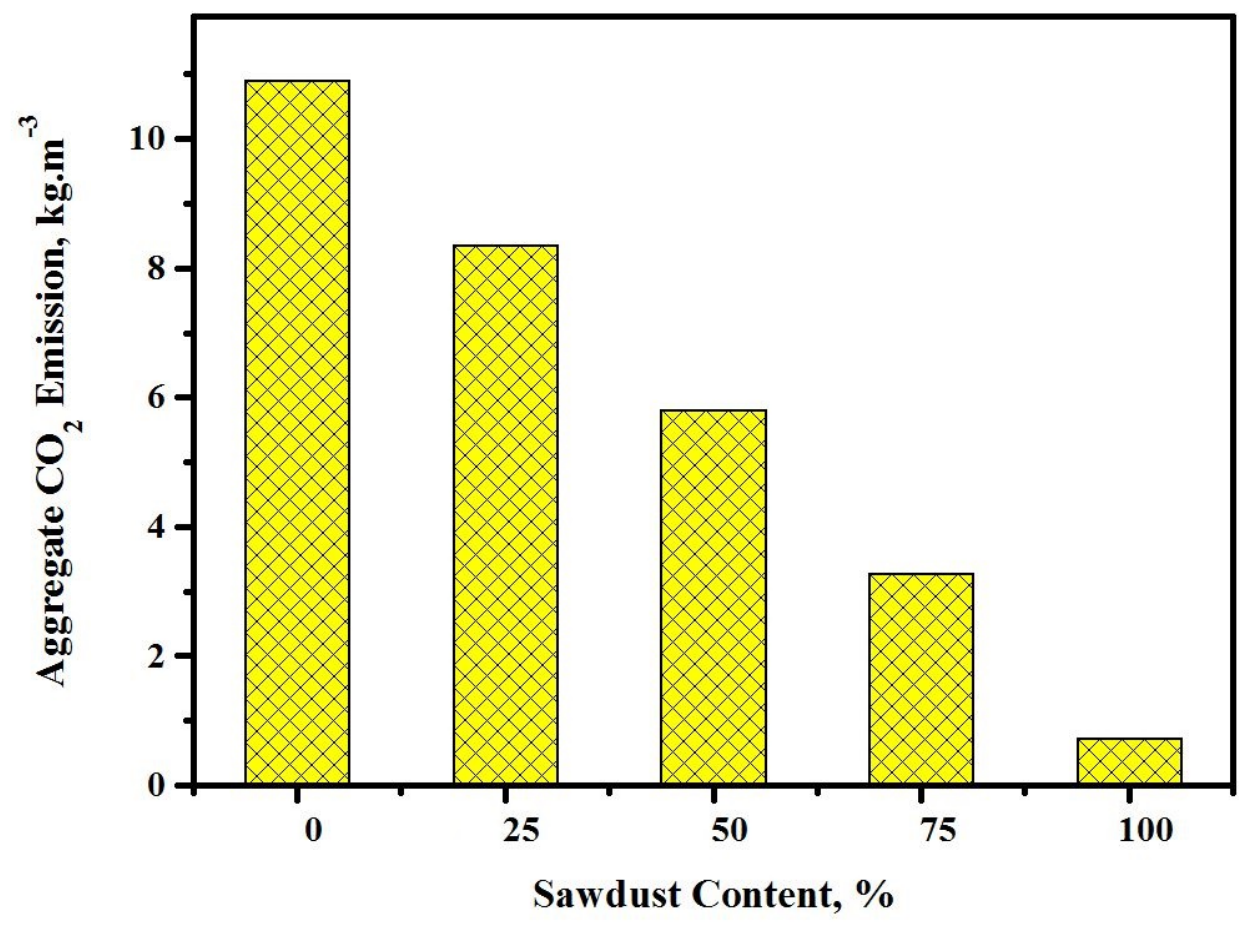

Figure 22. Effect of the sawdust content on the prepared concrete aggregate carbon dioxide emission.

Figure 23 shows the effect of sawdust replacing river sand and crushed gravel on the aggregate cost calculation of the prepared concrete. The usage of sawdust at a high level (100\%) as a substitute for sand and gravel also saved money. The price of material by weight depended on the life cycle (Table 4), which showed a direct influence on the final price of the concrete mixes made of aggregates. Furthermore, the cost of aggregates was reduced from 62.3 to $55.8,49.4,42.9$, and $36.6 \mathrm{RM} / \mathrm{m}^{3}$ with the rise in the sawdust contents as a substitute to natural aggregates at 0 to $25,50,75$, and $100 \%$, respectively. It was shown that, by implementing sawdust as an alternative to river sand and crushed gravel, a sustainable concrete can be achieved. 


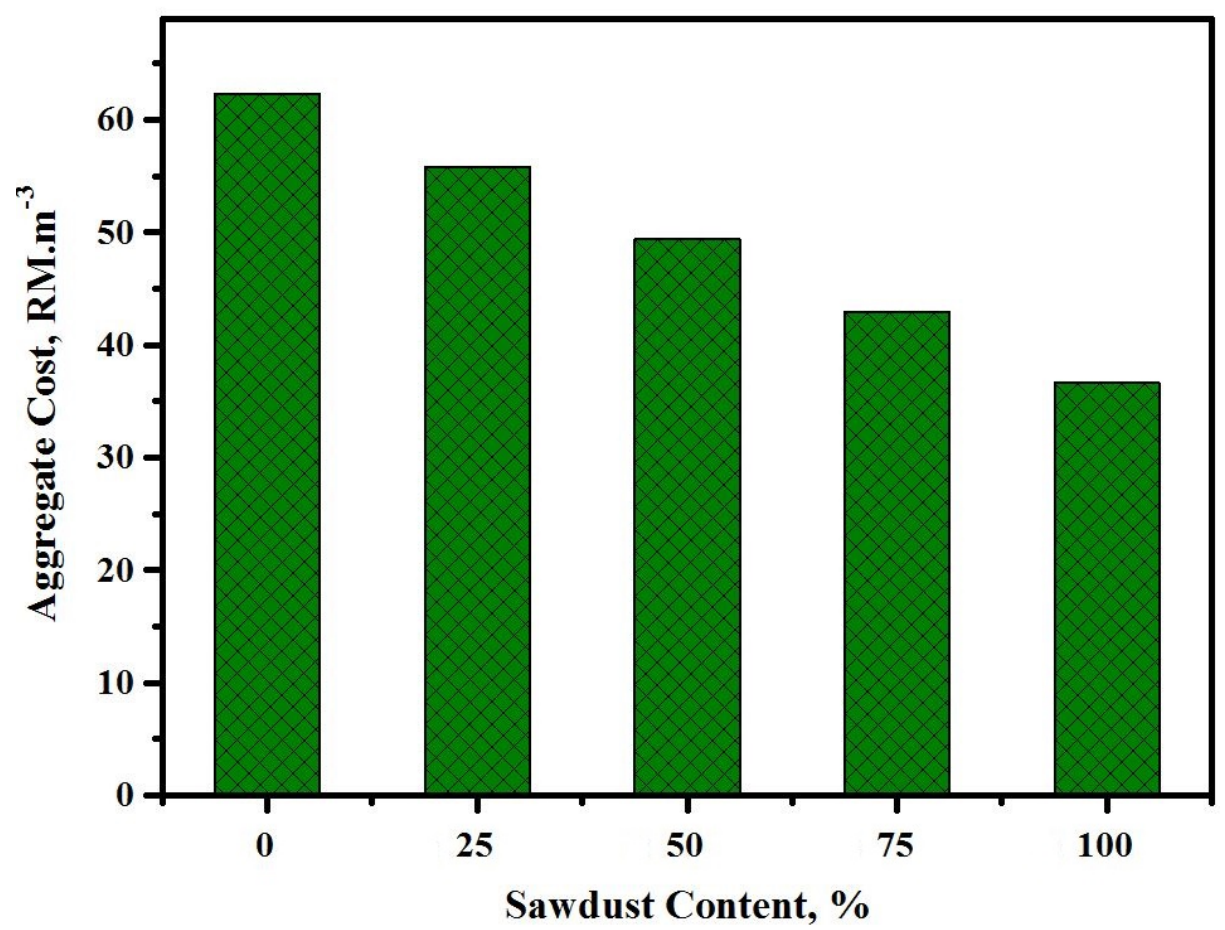

Figure 23. Effect of the sawdust content on the prepared concrete aggregate cost.

Figure 24 displays the energy consumption of the prepared concrete against the various sawdust contents. Depending on the life cycle and energy use of every substance, the total energy expenditure of every alkaline solution-activated concrete was evaluated. The energy utilization of the produced concretes was reduced with the addition of sawdust as a substitute for river sand/crushed gravel. In comparison to the energy use for the $0.15 \mathrm{GJ} / \mathrm{m}^{3}$ concrete with a $0 \%$ sawdust content, the values were reduced to $0.11,0.08,0.05$, and $0.022 \mathrm{GJ} / \mathrm{m}^{3}$ for mixes made with sawdust levels of $25,50,75$, and $100 \%$, respectively. However, all the alkaline solution-activated mixes with the maximum quantity of sawdust $(100 \%)$ required much lower energy than the one made with natural aggregates $\left(0.15 \mathrm{GJ} / \mathrm{m}^{3}\right)$. A low diesel utilization during the life cycle of sawdust can directly influence the final energy use of the proposed concretes. The low price, $\mathrm{CO}_{2}$ release, and energy utilization by the produced sawdust wastes were the primary factors that allowed attaining the desired sustainability of the alkaline solution-activated aggregates. 


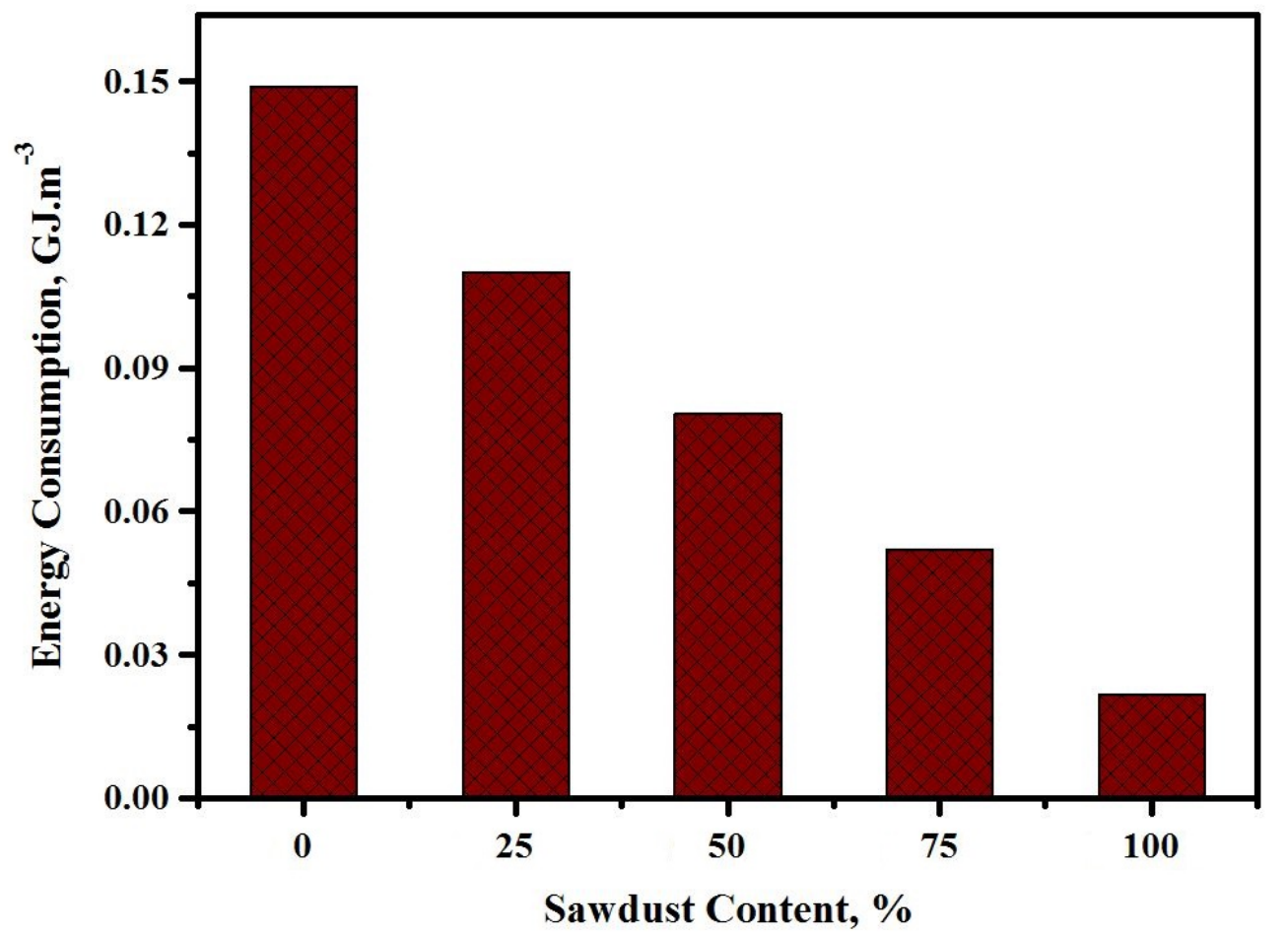

Figure 24. Energy consumption of the concretes prepared at various sawdust contents.

\section{Conclusions}

The conclusions of this study are as follows:

(1) Replacing the natural aggregates, including river sand and gravel, with sawdust wastes could influence the flow ability, setting time, and CS development. The slump of the prepared concrete dropped from 130 to $74 \mathrm{~mm}$ with the rise in the corresponding sawdust levels from $0 \%$ to $100 \%$. Both the initial and final setting times were shorter than those of the control sample for the mixture containing $100 \%$ sawdust.

(2) The increment in the sawdust content from $0 \%$ to $100 \%$ negatively affects the strength gain. Meanwhile, the concretes prepared with $100 \%$ sawdust as a substitute for natural aggregates attained a satisfactorily high CS (48.6 MPa), allowing the proposed formulation to be suitable for diverse applications in the construction sector as a high-performance lightweight cement-free concrete.

(3) The ANN provided satisfactorily results for estimating the mechanical properties of AAMs compared to the ANN combined with the genetic algorithm and multiple linear regression models.

(4) Replacing the natural aggregates with sawdust led to a decrease in the drying shrinkage of the tested specimens.

(5) All the mixes prepared with sawdust as a substitute for natural fine/coarse aggregates exposed to elevated temperatures displayed a lower resistance and higher strength loss.

(6) The present findings proved that these new lightweight alkali solution-activated concretes are more environmentally friendly compared to conventional aggregate-based concrete. The replacement of sand and gravel aggregates with sawdust in the concrete matrices could produce a more efficient product with a lesser $\mathrm{CO}_{2}$ release, lower cost, and lower fuel use compared to one using natural aggregates.

(7) To reduce the cost of the alkaline solution-activated aggregates by $41.2 \%$ (RM 36.6) as opposed to RM 62.3 for natural aggregates, it is suggested to employ $100 \%$ sawdust as a substitute for river sand and crushed gravel. Thus, it is feasible to achieve a new sustainable concrete without using natural aggregates, which is effective for sustainable development. Furthermore, the proposed 
new formulation will remarkably reduce the $\mathrm{CO}_{2}$ release below the $85 \%$ fuel production obtained using natural aggregates.

(8) Apart from the environmental benefits, the designed concretes may offer a better-quality product with distinct mechanical characteristics, which is useful for several companies interested in lightweight concrete production. Briefly, sawdust wastes as an alternative to natural aggregates can offer several benefits and serve to accomplish the goal of sustainability in civil engineering construction with environmental friendliness.

Author Contributions: Conceptualization, H.A. and G.F.H.; methodology, G.F.H.; software, H.A.A.; validation, R.A., A.R.M.S. and A.A.; formal analysis, G.F.H.; investigation, G.F.H.; resources, H.A.; data curation, A.A.; writing of the original draft preparation, G.F.H.; writing of review and editing, A.R.M.S.; visualization, R.A.; supervision, A.R.M.S.; project administration, R.A.; funding acquisition, R.A. All authors have read and agreed to the published version of the manuscript.

Funding: This publication was also supported by Deanship of scientific research, Prince Sattam bin Abdulaziz University under research project No. 2020/01/16810.

Conflicts of Interest: The authors declare no conflict of interest.

\section{References}

1. Bratkovich, S.; Howe, J.; Bowyer, J.; Pepke, E.; Frank, M.; Fernholz, K. Municipal solid waste (Msw) and construction and demolition (C\&D) wood waste generation and recovery in the United States. Dovetail Partn. Minneap. 2014, 1, 1-16.

2. Röder, M.; Thornley, P. Waste wood as bioenergy feedstock. Climate change impacts and related emission uncertainties from waste wood based energy systems in the UK. Waste Manag. 2018, 74, 241-252. [CrossRef] [PubMed]

3. Brown, M.; Kearley, V. Role of wood waste as source of biomass fuel in the UK. Energy Mater. 2009, 4, 162-165. [CrossRef]

4. Ahmed, W.; Khushnood, R.A.; Memon, S.A.; Ahmad, S.; Baloch, W.L.; Usman, M. Effective use of sawdust for the production of eco-friendly and thermal-energy efficient normal weight and lightweight concretes with tailored fracture properties. J. Clean. Prod. 2018, 184, 1016-1027. [CrossRef]

5. Udoeyo, F.F.; Dashibil, P.U. Sawdust ash as concrete material. J. Mater. Civ. Eng. 2002, 14, 173-176. [CrossRef]

6. Sales, A.; De Souza, F.R.; Dos Santos, W.N.; Zimer, A.M.; Almeida, F.D.C.R. Lightweight composite concrete produced with water treatment sludge and sawdust: Thermal properties and potential application. Constr. Build. Mater. 2010, 24, 2446-2453. [CrossRef]

7. Oyedepo, O.J.; Oluwajana, S.D.; Akande, S.P. Investigation of properties of concrete using sawdust as partial replacement of sand. Civ. Environ. Res. 2014, 6, 35-42.

8. Adebakin, I.; Adeyemi, A.; Adu, J.; Ajayi, F.; Lawal, A.; Ogunrinola, O. Uses of sawdust as admixture in production of low-cost and lightweight hollow sandcrete blocks. Am. J. Sci. Ind. Res. 2012, 3, 458-463.

9. Boob, T. Performance of sawdust in low-cost sandcrete blocks. Am. J. Eng. Res. 2014, 3, 197-206.

10. Mageswari, M.; Vidivelli, B. The use of sawdust ash as fine aggregate replacement in concrete. J. Environ. Res. Dev. 2009, 3, 720-726.

11. Shah, K.W.; Huseien, G.F. Bond strength performance of ceramic, fly ash and GBFS ternary wastes combined alkali-activated mortars exposed to aggressive environments. Constr. Build. Mater. 2020, 251, 119088. [CrossRef]

12. Kubba, Z.; Hewayde, E.; Huseien, G.F.; Sam, A.R.M. Effect of Sodium Silicate Content on Setting Time and Mechanical Properties of Multi Blend Geopolymer Mortars. J. Eng. Appl. Sci. 2019, 14, 2262-2267. [CrossRef]

13. Pacheco-Torgal, F.; Abdollahnejad, Z.; Miraldo, S.; Kheradmand, M. Alkali-Activated Cement-Based Binders (AACBs) as Durable and Cost-Competitive Low- $\mathrm{CO}_{2}$ Binder Materials: Some Shortcomings that Need to Be Addressed; Butterworth-Heinemann: Oxford, UK, 2017.

14. Provis, J.L.; Palomo, A.; Shi, C. Advances in understanding alkali-activated materials. Cem. Concr. Res. 2015, 78, 110-125. [CrossRef]

15. Turner, L.K.; Collins, F.G. Carbon dioxide equivalent $\left(\mathrm{CO}_{2}-\mathrm{e}\right)$ emissions: A comparison between geopolymer and OPC cement concrete. Constr. Build. Mater. 2013, 43, 125-130. [CrossRef] 
16. Habert, G.; Ouellet-Plamondon, C. Recent update on the environmental impact of geopolymers. RILEM Tech. Lett. 2016, 1, 17-23. [CrossRef]

17. Ouellet-Plamondon, C.; Habert, G. Life cycle assessment (LCA) of alkali-activated cements and concretes. In Handbook of Alkali-Activated Cements, Mortars and Concretes; Elsevier: Amsterdam, The Netherlands, 2015; pp. 663-686.

18. Karakoç, M.B.; Türkmen, İ.; Maraş, M.M.; Kantarci, F.; Demirboğa, R.; Toprak, M.U. Mechanical properties and setting time of ferrochrome slag based geopolymer paste and mortar. Constr. Build. Mater. 2014, 72, 283-292. [CrossRef]

19. Huseien, G.F.; Mirza, J.; Ismail, M.; Ghoshal, S.; Ariffin, M.A.M. Effect of metakaolin replaced granulated blast furnace slag on fresh and early strength properties of geopolymer mortar. Ain Shams Eng. J. 2016, 9 , 1557-1566. [CrossRef]

20. Attanasio, A.; Pascali, L.; Tarantino, V.; Arena, W.; Largo, A. Alkali-Activated Mortars for Sustainable Building Solutions: Effect of Binder Composition on Technical Performance. Environments 2018, 5, 35. [CrossRef]

21. Shi, C.; Jiménez, A.F.; Palomo, A. New cements for the 21st century: The pursuit of an alternative to Portland cement. Cem. Concr. Res. 2011, 41, 750-763. [CrossRef]

22. Ranjbar, N.; Mehrali, M.; Alengaram, U.J.; Metselaar, H.S.C.; Jumaat, M.Z. Compressive strength and microstructural analysis of fly ash/palm oil fuel ash based geopolymer mortar under elevated temperatures. Constr. Build. Mater. 2014, 65, 114-121. [CrossRef]

23. Salih, M.A.; Farzadnia, N.; Ali, A.A.A.; Demirboga, R. Development of high strength alkali activated binder using palm oil fuel ash and GGBS at ambient temperature. Constr. Build. Mater. 2015, 93, 289-300. [CrossRef]

24. Huseien, G.F.; Mirza, J.; Ismail, M.; Hussin, M.W.; Ariffin, M.A.M. Potential use coconut milk as alternative to alkali solution for geopolymer production. J. Teknol. 2016, 76, 132-139. [CrossRef]

25. Chindaprasirt, P.; Chareerat, T.; Hatanaka, S.; Cao, T. High-strength geopolymer using fine high-calcium fly ash. J. Mater. Civ. Eng. 2010, 23, 264-270. [CrossRef]

26. Phoo-ngernkham, T.; Sata, V.; Hanjitsuwan, S.; Ridtirud, C.; Hatanaka, S.; Chindaprasirt, P. High calcium fly ash geopolymer mortar containing Portland cement for use as repair material. Constr. Build. Mater. 2015, 98, 482-488. [CrossRef]

27. Somna, K.; Jaturapitakkul, C.; Kajitvichyanukul, P.; Chindaprasirt, P. NaOH-activated ground fly ash geopolymer cured at ambient temperature. Fuel 2011, 90, 2118-2124. [CrossRef]

28. Nath, P.; Sarker, P.K. Use of OPC to improve setting and early strength properties of low calcium fly ash geopolymer concrete cured at room temperature. Cem. Concr. Compos. 2015, 55, 205-214. [CrossRef]

29. Suwan, T.; Fan, M. Influence of OPC replacement and manufacturing procedures on the properties of self-cured geopolymer. Constr. Build. Mater. 2014, 73, 551-561. [CrossRef]

30. Pangdaeng, S.; Phoo-ngernkham, T.; Sata, V.; Chindaprasirt, P. Influence of curing conditions on properties of high calcium fly ash geopolymer containing Portland cement as additive. Mater. Des. 2014, 53, 269-274. [CrossRef]

31. Imbabi, M.S.; Carrigan, C.; McKenna, S. Trends and developments in green cement and concrete technology. Int. J. Sustain. Built Environ. 2012, 1, 194-216. [CrossRef]

32. Kubba, Z.; Huseien, G.F.; Sam, A.R.M.; Shah, K.W.; Asaad, M.A.; Ismail, M.; Mirza, J. Impact of curing temperatures and alkaline activators on compressive strength and porosity of ternary blended geopolymer mortars. Case Stud. Constr. Mater. 2018, 9, 205-220. [CrossRef]

33. Huseien, G.F.; Shah, K.W. Durability and life cycle evaluation of self-compacting concrete containing fly ash as GBFS replacement with alkali activation. Constr. Build. Mater. 2020, 235, 117458. [CrossRef]

34. Mhaya, A.M.; Huseien, G.F.; Abidin, A.R.Z.; Ismail, M. Long-term mechanical and durable properties of waste tires rubber crumbs replaced GBFS modified concretes. Constr. Build. Mater. 2020, 256, 119505. [CrossRef]

35. Samadi, M.; Shah, K.W.; Huseien, G.F.; Lim, N.H.A.S. Influence of Glass Silica Waste Nano Powder on the Mechanical and Microstructure Properties of Alkali-Activated Mortars. Nanomaterials 2020, 10, 324. [CrossRef] [PubMed]

36. Rashad, A.M. Properties of alkali-activated fly ash concrete blended with slag. Iran. J. Mater. Sci. Eng. 2013, 10, 57-64. 
37. Rakhimova, N.; Rakhimov, R. A review on alkali-activated slag cements incorporated with supplementary materials. J. Sustain. Cem. Based Mater. 2014, 3, 61-74. [CrossRef]

38. Chi, M.; Huang, R. Binding mechanism and properties of alkali-activated fly ash/slag mortars. Constr. Build. Mater. 2013, 40, 291-298. [CrossRef]

39. Garcia-Lodeiro, I.; Fernandez-Jimenez, A.; Palomo, A. Hydration kinetics in hybrid binders: Early reaction stages. Cem. Concr. Compos. 2013, 39, 82-92. [CrossRef]

40. Ismail, I.; Bernal, S.A.; Provis, J.L.; Hamdan, S.; van Deventer, J.S. Microstructural changes in alkali activated fly ash/slag geopolymers with sulfate exposure. Mater. Struct. 2013, 46, 361-373. [CrossRef]

41. Ismail, I.; Bernal, S.A.; Provis, J.L.; San Nicolas, R.; Hamdan, S.; van Deventer, J.S. Modification of phase evolution in alkali-activated blast furnace slag by the incorporation of fly ash. Cem. Concr. Compos. 2014, 45, 125-135. [CrossRef]

42. Guerrieri, M.; Sanjayan, J.G. Behavior of combined fly ash/slag-based geopolymers when exposed to high temperatures. Fire Mater. Int. J. 2010, 34, 163-175. [CrossRef]

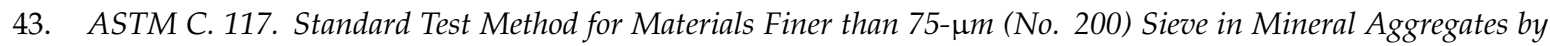
Washing; ASTM International: West Conshohocken, PA, USA, 2003.

44. ASTM C. 33, Standard Specification for Concrete Aggregates; ASTM International: West Conshohocken, PA, USA, 1994.

45. Singh, M.; Siddique, R. Strength properties and micro-structural properties of concrete containing coal bottom ash as partial replacement of fine aggregate. Constr. Build. Mater. 2014, 50, 246-256. [CrossRef]

46. Rafieizonooz, M.; Mirza, J.; Salim, M.R.; Hussin, M.W.; Khankhaje, E. Investigation of coal bottom ash and fly ash in concrete as replacement for sand and cement. Constr. Build. Mater. 2016, 116, 15-24. [CrossRef]

47. Huseien, G.F.; Memon, R.P.; Kubba, Z.; Sam, A.R.M.; Asaad, M.A.; Mirza, J. Mechanical, thermal and durable performance of wastes sawdust as coarse aggregate replacement in conventional concrete. J. Teknol. 2019, 81, 151-161. [CrossRef]

48. Duan, P.; Yan, C.; Zhou, W.; Luo, W. Fresh properties, mechanical strength and microstructure of fly ash geopolymer paste reinforced with sawdust. Constr. Build. Mater. 2016, 111, 600-610. [CrossRef]

49. Memon, R.P.; Awal., A.S.M.; Sam, A.R.M.; Achakzai, L. Mechanical and Thermal Properties of Sawdust Concrete. Ph.D. Thesis, Universiti Teknologi Malaysia, Johor Bahru, Malaysia, 2016.

50. Sales, A.; de Souza, F.R.; Almeida, F.d.C.R. Mechanical properties of concrete produced with a composite of water treatment sludge and sawdust. Constr. Build. Mater. 2011, 25, 2793-2798. [CrossRef]

51. Islam, A.; Alengaram, U.J.; Jumaat, M.Z.; Bashar, I.I. The development of compressive strength of ground granulated blast furnace slag-palm oil fuel ash-fly ash based geopolymer mortar. Mater. Des. (1980-2015) 2014, 56, 833-841. [CrossRef]

52. Kanojia, A.; Jain, S.K. Performance of coconut shell as coarse aggregate in concrete. Constr. Build. Mater. 2017, 140, 150-156. [CrossRef]

53. Martínez-García, C.; González-Fonteboa, B.; Martínez-Abella, F.; Carro-López, D. Performance of mussel shell as aggregate in plain concrete. Constr. Build. Mater. 2017, 139, 570-583. [CrossRef]

54. González-Fonteboa, B.; Martínez-Abella, F.; Herrador, M.F.; Seara-Paz, S. Structural recycled concrete: Behaviour under low loading rate. Constr. Build. Mater. 2012, 28, 111-116. [CrossRef]

55. Andrade, L.B.; Rocha, J.; Cheriaf, M. Evaluation of concrete incorporating bottom ash as a natural aggregates replacement. Waste Manag. 2007, 27, 1190-1199. [CrossRef]

56. Huseien, G.F.; Shah, K.W. Performance evaluation of alkali-activated mortars containing industrial wastes as surface repair materials. J. Build. Eng. 2020, 30, 101234. [CrossRef]

57. Juarez, C.; Fajardo, G.; Monroy, S.; Duran-Herrera, A.; Valdez, P.; Magniont, C. Comparative study between natural and PVA fibers to reduce plastic shrinkage cracking in cement-based composite. Constr. Build. Mater. 2015, 91, 164-170. [CrossRef]

58. Tong, Y.; Zhao, S.; Ma, J.; Wang, L.; Zhang, Y.; Gao, Y. Improving cracking and drying shrinkage properties of cement mortar by adding chemically treated luffa fibres. Constr. Build. Mater. 2014, 71, 327-333. [CrossRef]

59. Aigbomian, E.P.; Fan, M. Development of Wood-Crete building materials from sawdust and waste paper. Constr. Build. Mater. 2013, 40,361-366. [CrossRef]

60. Glé, P.; Gourdon, E.; Arnaud, L. Acoustical properties of materials made of vegetable particles with several scales of porosity. Appl. Acoust. 2011, 72, 249-259. [CrossRef] 
61. Chen, Y.; Yu, Q.; Brouwers, H. Acoustic performance and microstructural analysis of bio-based lightweight concrete containing miscanthus. Constr. Build. Mater. 2017, 157, 839-851. [CrossRef]

62. Aliabdo, A.A.; Abd Elmoaty, M.; AbdElbaset, M.M. Utilization of waste rubber in non-structural applications. Constr. Build. Mater. 2015, 91, 195-207. [CrossRef]

63. Sukontasukkul, P. Use of crumb rubber to improve thermal and sound properties of pre-cast concrete panel. Constr. Build. Mater. 2009, 23, 1084-1092. [CrossRef]

64. Park, S.B.; Seo, D.S.; Lee, J. Studies on the sound absorption characteristics of porous concrete based on the content of recycled aggregate and target void ratio. Cem. Concr. Res. 2005, 35, 1846-1854. [CrossRef]

65. Kim, H.-K.; Jeon, J.; Lee, H.-K. Workability, and mechanical, acoustic and thermal properties of lightweight aggregate concrete with a high volume of entrained air. Constr. Build. Mater. 2012, 29, 193-200. [CrossRef]

66. Liu, H.-Y.; Wu, H.-S.; Chou, C.-P. Study on engineering and thermal properties of environment-friendly lightweight concrete made from Kinmen oyster shells and sorghum waste. Constr. Build. Mater. 2020, 246, 118367. [CrossRef]

67. Clarke, D.R. Materials selection guidelines for low thermal conductivity thermal barrier coatings. Surf. Coat. Technol. 2003, 163, 67-74. [CrossRef]

68. Topçu, İ.B.; Uygunoğlu, T. Properties of autoclaved lightweight aggregate concrete. Build. Environ. 2007, 42, 4108-4116. [CrossRef]

Publisher's Note: MDPI stays neutral with regard to jurisdictional claims in published maps and institutional affiliations. 